\title{
Assessing the Relative Performance of Microwave-Based Satellite Rain Rate Retrievals Using TRMM Ground Validation Data
}

\author{
David B. Wolff ${ }^{1,2}$ and Brad L. Fisher ${ }^{1,2}$ \\ ${ }^{1}$ Science Systems \& Applications, Inc, Lanham, Maryland \\ ${ }^{2}$ NASA Goddard Space Flight Center, Greenbelt, Maryland
}

Corresponding Author's Address:

David B. Wolff

NASA/GSFC, Code 613.1, Greenbelt, MD 20771

David.B.Wolff@nasa.gov 


\begin{abstract}
Space-borne microwave sensors provide critical rain information used in several global multi-satellite rain products, which in turn are used for a variety of important studies, including landslide forecasting, flash flood warning, data assimilation, climate studies, and validation of model forecast of precipitation. This study employs four years (2003-2006) of satellite data to assess the relative performance and skill of SSM/I (F13, F14 and F15), AMSU-B (N15, N16 and N17), AMSR-E (AQUA) and the TRMM Microwave Imager (TMI) in estimating surface rainfall based on direct instantaneous comparison with ground-based rain estimates from Tropical Rainfall Measuring Mission (TRMM) Ground Validation (GV) sites at Kwajalein, Republic of the Marshall Islands (KWAJ) and Melbourne, Florida (MELB). The relative performance of each of these satellites is examined via comparisons with GV radar-based rain rate estimates. Because underlying surface terrain is known to affect the relative performance of the satellite algorithms, the data for MELB was further stratified into ocean, land and coast categories using a $0.25^{\circ}$ terrain mask.
\end{abstract}

Of all the satellite estimates compared in this study, TMI and AMSR-E exhibited considerably higher correlations and skills in estimating/observing surface precipitation. While SSM/I and AMSU-B exhibited lower correlations and skills for each of the different terrain categories, the SSM/I absolute biases trended slightly lower than AMSRE over ocean, where the observations from both emission and scattering channels were used in the retrievals. AMSU-B exhibited the least skill relative to GV in all of the relevant statistical categories, and an anomalous spike was observed in the probability 
distribution functions near $1.0 \mathrm{~mm} \mathrm{hr}^{-1}$. This statistical artifact appears to be related to attempts by algorithm developers to include some lighter rain rates, not easily detectable by its scatter-only frequencies. AMSU-B, however, agreed well with GV when the matching data was analyzed on monthly scales. These results signal developers of global rainfall products, such as the TRMM Multi-Satellite Precipitation Analysis (TMPA), and the Climate Data Center's Morphing (CMORPH) technique, that care must be taken when incorporating data from these input satellite estimates in order to provide the highest quality estimates in their products. 


\section{Introduction}

Precipitation is a key component of the Earth's hydrological cycle and an important factor in climate change because of its association with the global transport and distribution of water and latent heat. Until the advent of meteorological satellites and the development of remote sensing techniques for measuring precipitation from space, there

was no observational system capable of providing accurate estimates of precipitation at global scales. Precipitation, moreover, is one of the most difficult physical quantities to measure accurately due to extreme variability rainfall in time and space and insufficient monitoring of the planet's oceans.

Since the early 1970 s, satellites have been used to quantitatively estimate precipitation by observing the emission and scattering processes associated with clouds and precipitation in the atmosphere. Multi-channel passive microwave remote sensing techniques hold the most promise because these instruments sample rain systems at different depths, and subsequently can be used to physically probe precipitation in its different thermodynamic states. Since the launch of the single channel Electrically Scanning Microwave Radiometer (ESMR) aboard the Nimbus 5 in 1972, many other multi-channel microwave platforms have been deployed in space and used to estimate surface rainfall over a significant fraction of the earth's surface.

A single orbiting platform does not collect enough rain information to accurately estimate precipitation everywhere on the earth's surface. The Tropical Rainfall Measuring Mission (TRMM) TRMM Microwave Imager (TMI), United States Defense Department's Special Sensor Microwave/Imager (SSM/I), National Oceanic and Atmospheric Administration (NOAA) Advanced Microwave Scanning Radiometer- EOS 
(AMSR-E) and Advanced Microwave Sounding Unit (AMSU), for example, each provide about two samples per day from any localized region of the earth's surface. However, statistical sampling on regional scales can be significantly improved by combining the rain information from a multitude of satellites.

These passive microwave satellite platforms are currently being used to develop high-resolution global estimates of precipitation using varying types of merging of the various satellite observations, including the TRMM Multi-Satellite Precipitation Analysis (TMPA) (Huffman et al. 2007) the Climate Data Center's Morphed (CMORPH) (Joyce et al. 2004) and the Precipitation Estimation from Remotely Sensed Information using Artificial Neural Networks (PERSIANN, Hsu et al. 1997, Sorooshian et al. 2005) rain products, all of which provide near-global 3-hourly estimates at $0.25^{\circ}$ resolution. Identifying the strengths and weaknesses of the satellite measurements associated with each sensor class is critical to understanding the measurement and error characteristics of the multi-satellite products used in various applications, including climate modeling.

Rain estimates determined from ground-based sensors provide an independent source of validation for inferring the error characteristics of estimates derived from space-borne remote sensors. However, to eliminate the temporal sampling component of the error budget, it is necessary to match the data in time and space. In previous studies, Ferraro and Marks (1995) estimated errors in SSM/I/ inferred rain rates by spatiotemporally matching SSM/I data obtained from F8 and F11 to radar estimates collected in the United States, the United Kingdom and Japan. Lin and Hou (2008) validated rain estimates from eight microwave sensors (TMI, F13, F14, F15, AMSR, N15, N16, N17) by comparing near-coincident measurements from the TRMM PR. 
The Tropical Rainfall Measuring Mission (TRMM) satellite program has been operational since its launch in November 1997. As part of the TRMM program, a Ground Validation (GV) program was established in order to provide validation of the TRMM satellite estimates. The GV program established four principal sites that use both ground-based radars, and networks of rain gauges and disdrometers to provide highresolution rain rate measurements, both temporally and spatially, for such efforts. Wolff et al. (2005) provide an overview of the TRMM GV program. Wolff \& Fisher (2008) used TRMM GV data to show the relative accuracy of the three principal TRMM satellite retrievals derived from the Precipitation Radar (PR) and the TRMM Microwave Imager (TMI). Significant effort has been made towards improving the quality of the TRMM GV rain rate estimates. In particular, success in post-calibrating the radar data from Kwajalein, Republic of the Marshall Islands (Silberstein et al. 2008), has provided for a high quality, open ocean data set for comparison to TRMM and other satellites precipitation retrievals (Marks et al. 2008).

In this study, we use four years (2003-2006) of GV data from Kwajalein, Republic of the Marshall Islands (KWAJ) and Melbourne, Florida (MELB), to assess the relative performance of satellite precipitation estimates from seven polar-orbiting satellites and the TRMM Microwave Imager (TMI), which flies in sun-asynchronous orbit. The comparisons are based on instantaneous estimates, all averaged to $0.25^{\circ}$. Using GV as a reference, we will show both the similarities of the various satellite estimates, as well as some fundamental differences, due to both algorithmic and instrumental issues. Although considerable effort has been made to produce the highest quality and most accurate rain rate data from the GV observations, the authors make no 
claim as to the absolute accuracy of the GV rain data, and thus offer GV as a reference, from which the relative performance of the satellite estimates can be made.

2. Satellite microwave radiometers: SSM/I, AMSU-B and AMSR-E

\section{a. Data Sources: General}

This study analyzes data collected from multi-channel microwave rain sensors on board eight space-borne satellites. The rain sensors involved in this study include AMSUB on N15, N16, and N17 satellites, SSM/I on F13, F14 and F15 satellites, AMSR-E on the Aqua satellite, and the TMI on the TRMM satellite. Each platform samples rain information across a broad range of discrete frequency bands in the microwave spectrum. Table 1 shows the frequency and polarization of the microwave channels for each sensor class.

Level II AMSR-E data and AMSU-B data were acquired from the National Snow and Ice Data Center (NSIDC) in their native resolution. This data was then gridded to a resolution of $0.25^{\circ}$ using software developed by Eric Nelkin at the Goddard Space Flight Center. SSM/I was obtained from the Goddard Earth Science Distributed Active Archive Center (DAAC), which was already gridded at $0.25^{\circ}$. The TMI data was gridded to $0.25^{\circ}$ by the TRMM Science Data and Information System (TSDIS) for use in this study, at the special request of the authors of this study. Once the complete record of this 0.25 TRMM

$3 \mathrm{G} 68$ data is completed, TSDIS will offer it to the general public as well (E. Stocker, personal communication, 2008).

b. SSM/I, TMI and AMSR-E 
The SSM/I, TMI and AMSR-E are conically scanning microwave radiometers with similar physical characteristics. The SSM/I were designed for the U.S. Air Force Defense Meteorological Satellite Program (DMSP), which began in June 1987 with the successful launch of F8. SSM/I data for this study were obtained from F13, F14 and F15, which were launched in 1995, 1997 and 1999, respectively. The DMSP satellites fly in a near circular polar orbit at a nominal altitude of $865 \mathrm{~km}$ and an orbital period of about 102 minutes.

The SSM/I is equipped with seven linearly polarized channels, which sample microwave radiances at four different frequencies over a swath of about $1400 \mathrm{~km}$. Dually polarized measurements - horizontal and vertical - are collected at 19.35, 37.0 and 85.5 $\mathrm{GHz}$, while the channel centered on the water vapor line at $22.24 \mathrm{GHz}$ measures only vertically polarized radiances (Prabhakara 1992, Kummerow and Giglio 1994).

The TRMM satellite was launched in November 1997 with a payload that included both a passive microwave sensor (TMI), and an active precipitation radar (PR). The TMI was based on the original design of the SSM/I, with a few additions and modifications: the TMI added two dually polarized emission channels at $10.7 \mathrm{GHz}$, while the TMI's $21.3 \mathrm{GHz}$ channel was shifted slightly off center of the water vapor line to avoid saturation (Kummerow 1998). Both the TMI and SSM/I only allocate one vertically polarized channel to the water vapor band at 22.3 .

TRMM flies in a sun-asynchronous, low-earth orbit, with an inclination angle of 35 degrees and a mean altitude of $402 \mathrm{~km}$. Because TRMM flies in a lower earth orbit than the other satellites, the TMI covers a smaller swath of $878 \mathrm{~km}$ and has a smaller footprint at each frequency. On regional scales, the TRMM satellite, unlike the polar 
orbiters, which collect two samples per day at about the same time, precesses through the entire diurnal cycle over a period of about 46 days.

AMSR-E is flown onboard the Aqua satellite and is part of the multi-satellite Earth Observing System (EOS). Aqua was launched in May 2002, and orbits at an altitude of $705 \mathrm{~km}$ with an orbital period of about 99 minutes. AMSR-E has 12 dually polarized channels that sample microwave radiances at six different frequencies ranging from 6.9 to $89 \mathrm{GHz}$ across a swath of about $1445 \mathrm{~km}$ (see Table 2). AMSR-E is similar in design to the TMI, but includes two additional channels at $6.9 \mathrm{GHz}$, however poor spatial resolution limits the usefulness of these channels in rainfall estimation. AMSR-E also includes a horizontally polarized channel at $23.8 \mathrm{GHz}$, with the off-center shift from the water vapor line towards a slightly higher frequency.

Rain rate retrievals for the SSM/I, TMI AMSR-E were carried out using Version 6 of the Goddard Profiling (GPROF) algorithm described by Kummerow et al. (1996), Kummerow et al. (2001), Wilheit et al. (2003) and other, although it should be noted that minor modifications of the basic Version algorithm are employed by the algorithm developers for each platform. However, in general, the GPROF algorithm retrieves both instantaneous rainfall and the vertical latent heating structure by constructing a vertical profile from the observed brightness temperatures in each channel. Rain rates are calculated using a Bayesian inversion procedure, which relates the retrieved profile, $\mathbf{T b}$, to a simulated rain profile $\mathbf{R}$ :

$$
\operatorname{Pr}(\boldsymbol{R} \mid \boldsymbol{T} \boldsymbol{b})=\operatorname{Pr}(\boldsymbol{R})+\operatorname{Pr}(\boldsymbol{T} \boldsymbol{b} \mid \boldsymbol{R})
$$

Given the observed profile $\mathbf{T b}$, Eqn. 1 relates the conditional probability of observing a particular profile $\mathbf{R}$ to the sum of the two probabilities on the right hand side. The first 
term is derived from cloud-resolving models and describes the probability that a certain rain rate profile $\mathbf{R}$ will be observed. The second term is obtained by matching radiative transfer calculations and describes the Bayesian probability of observing the brightness temperature $\mathbf{T b}$ given the rain rate profile $\mathbf{R}$ and (Kummerow et al. 2001, Wilheit et al. 2003).

The estimation of surface rain rates from space-borne microwave sensors critically depends on the ability to separate emission and scattering radiances due to rain and clouds from the radiative upwelling emanating from the earth's surface (Weinman and Guetter 1977). The task is complicated by the fact that radiative properties of the land and ocean surfaces differ significantly. Whereas the ocean surface is radiometrically cold and homogeneous, the land surface is radiometrically warm, and emissivities over land can be highly variable in time and space. Coastal regions, which include radiative contributions from both ocean and land, require even more complicated "physics" and assumptions and yield the most uncertain results.

Consequently, GPROF handles the calculation of rain rates differently depending on the underlying terrain. First, each pixel sampled is classified as ocean, land or coast using a fixed surface-terrain mask that was originally developed at $1 / 6^{\circ}$ degree resolution for the TRMM TMI. For KWAJ and MELB, the surface-terrain masks used in this study are shown in Figs. 2a and 2b, respectively. The "ocean" algorithm constructs a brightness temperature vertical profile using all of the brightness temperature information collected from the available channels, and thus more physically based because the low frequency emission channels more directly probe the precipitable water at the cloud base. The land and coast algorithms, on the other hand, are empirically based because they rely on the 
high frequency scattering channels $(85.5 \mathrm{GHz}$ for $\mathrm{SSM} / \mathrm{I}$ and TMI and $89.0 \mathrm{GHz}$ for AMSR-E), which are correlated with ice scattering processes at the cloud top. Over land and coast the emission spectrum from the surface is too warm and highly variable to distinguish from the rain signal in the atmosphere.

The GPROF land algorithm is based the National Environmental Satellite Data and Information Service (NESDIS). A more complete description of the land algorithm can be found in Ferraro (1997) and McCollum and Ferraro (2003). The operational coast algorithm was originally developed from Goddard Scattering Algorithm (GSCAT) and is described in McCollum and Ferraro (2005). Again, minor differences in the various GPROF algorithms employed by the various platforms are common.

c. AMSU

The Advanced Microwave Sounding Unit (AMSU) is a cross-track scanning observational system consisting of two multi-channel radiometers: AMSU-A and AMSUB. The AMSU-B sensor package was designed for probing the temperature and moisture structure of the atmosphere. It is also used being in the estimation of surface rainfall. This sensor package is flown aboard the NOAA-15 (N15), NOAA-16 (N16) and NOAA-17 (N17) satellites, and collects radiances between $48^{\circ} \mathrm{S}$ and $48^{\circ} \mathrm{N}$ at an altitude of $850 \mathrm{~km}$. (swath $1650 \mathrm{~km}$ )

AMSU-A has fifteen channels that range from 23.8 to $89.0 \mathrm{GHz}$ and AMSU-B has 5 channels ranging from 89.0 to $183.31 \mathrm{GHz}$. AMSU-B rainfall estimates use the information from channels 1 and 2 on AMSU-A, at 23.8 and $31.4 \mathrm{GHz}$ and channels 1-5 on AMSU-B at 89, 150 and $183 \mathrm{GHz}$ (there are three channels at $183 \mathrm{GHz}$ with different band pass filters). All nineteen channels are vertically polarized. 
The AMSU-B rain algorithm is based on the correlation between surface rain rate (RR) and ice scattering aloft as observed by the high frequency channels (Spencer 1989, Weng et al. 2003, Qiu et al. 2005). The algorithm simultaneously retrieves the ice water path (IWP) and the effective particle diameter $\mathrm{D}_{\mathrm{e}}$. The IWP is obtained using a twostream approximation to the radiative transfer equation. The $23.8 \mathrm{GHz}$ and $31.4 \mathrm{GHz}$ emission channels on AMSU-A are also used to infer the cloud-base and cloud-top brightness temperatures. Rain rates are determined based on a non-linear relationship between RR and IWP computed using the fifth generation Mesoscale Model (MM5) developed by Penn State University and the National Center for Atmospheric Research (NCAR). The mean IWP-RR relation can statistically determined and assumes the form

$$
\boldsymbol{R} R=a_{0}+a_{1} I W P+a_{2} I W P^{2}
$$

where $\mathrm{a}_{0}, \mathrm{a}_{1}$ and $\mathrm{a}_{2}$ estimated constants.

Multiple scattering channels are also needed in order to simultaneously determine both IWP and $D_{e}$ without ambiguity (Weng 2003). Of all the microwave sensors, the AMSU-B covers the broadest region of the microwave spectrum. It is expected that the additional scattering channels at 150 and $183 \mathrm{GHz}$ would improve the estimate of surface rain rates over land.

\section{GV Data}

The GV data for this study used the official TRMM 2A-53 rain products for KWAJ and MELB produced by the TRMM Satellite Validation Office and available from the Goddard Earth Sciences Data and Information Services Center (GES DISC). The $2 \mathrm{~A}-53$ product provides instantaneous rain rates at $2 \mathrm{~km} \times 2 \mathrm{~km}$ horizontal 
resolution, extending $150 \mathrm{~km}$ from the respective $\mathrm{GV}$ radar. The $\mathrm{GV}$ radar data was processed using official Version 5 (MELB) and Version 7 (KWAJ). The algorithm applies the Window Probability Matching Method (Rosenfeld, 1995) to the statistical determination of rain rates from radar reflectivities. The GV processing system and descriptions of the GV algorithms are detailed in Wolff et al. 2005. We note that the KWAJ data, now Version 7, has undergone significant improvement from previous versions, after the application of the Relative Calibration Adjustment (RCA) technique was applied to correct calibration and pointing angle errors in the raw reflectivity data (Silberstein, 2008). The RCA method and its application to the KWAJ reflectivity data are described in Marks et al. 2008. Marks et al. convincingly demonstrate that the yearto-year radar-rainfall relationships converge, as was to be expected from long-term analysis of drop size distributions. Further, Marks et al. 2008 show that the mean difference between the KWAJ reflectivity estimates to be within $\pm 1 \mathrm{~dB}$ of the well calibrated and stable TRMM Precipitation Radar (PR) (Takahashi et al. 2003).

\section{Data Analysis: Description}

This study assesses the relative performance of the eight microwave sensors for the GV sites at KWAJ and MELB over a four-year period from 2003 to 2006. The validation strategy was to inter-compare ground and space based measurements by matching the retrieved instantaneous rain rates from each sensor to the GV rain rates

during satellite overpasses of the GV site. The matched rain rates were averaged at a gridresolution of $0.25^{\circ} \times 0.25^{\circ}$ (latitude $\mathrm{x}$ longitude). The key advantage of matching the satellite and GV data sets at instantaneous scales is that the temporal sampling error 
associated with non-continuous regional sampling by the orbiting satellites can be eliminated as a major source of uncertainty. Although there are myriad problem with estimating precipitation with radar data, such as anomalous propagation, ground clutter, beam filling, range effects, improper rain/reflectivity relationships etc., the authors of this study suggest that rather than rely too heavily on simple statistics such as biases, which might occur from over- or under-estimation by the radar, the satellite or both, one should make these comparisons using a variety of statistical tests in order to determine how the relative performance of the various satellite estimates vary. This validation strategy uses the ground data as an empirical reference for assessing the relative performance of passive microwave-based rain retrievals at instantaneous scales.

The PMM method used to generate radar-derived rain rates from measured reflectivity depends on the instantaneous rain rate information from an extended network of gauges as a function of range. Figure $1 \mathrm{a}$ and $1 \mathrm{~b}$ show the radar and gauge networks for KWAJ and MELB, respectively. The gauge network at KWAJ only extends out to about the $100 \mathrm{~km}$ range ring shown in Fig 1a, whereas in Fig. 1b, it can be seen that the gauge network at MELB extends well beyond the outer $150 \mathrm{~km}$ range ring. In the case of KWAJ, satellite rain rates were only matched out to $100 \mathrm{~km}$ but were extended out to 150 $\mathrm{km}$ in the case of MELB.

Each $0.25^{\circ}$ grid box, as mentioned in the previous section, was classified as land, coast according to a surface terrain mask. The original TRMM terrain map was produced at a scale of $1 / 6^{\circ}$, whereas the matching in the study was at $0.25^{\circ}$. For classification purposes, the mask was interpolated to $0.25^{\circ}$. For cases where more than one terrain type existed, the classification was determined based on a "majority rules" criterion. The 
$0.25^{\circ}$ classifications for KWAJ and MELB are shown in Fig. 2a and 2b, respectively. KWAJ is a pure, open ocean site and as seen in Fig. 2a, every 0.25 grid box is classified as ocean. MELB, on the other hand, contains all three classifications, with about 1/3 of the boxes classified as coast

The seven polar orbiting satellites and TRMM differ fundamentally in their temporal sampling of the atmosphere. For a given grid box, each of the polar orbiters collect two samples per day at the about the same nominal times, and thus mean rain rate inferred from these observations incurs an intrinsic diurnal bias. TRMM on the other hand, reduces the diurnal bias by precessing through the diurnal cycle in a period of about 46 days. Thus, over the four-year period employed in this study, TRMM is able to well capture the diurnal cycle at both KWAJ and MELB. To illustrate the potential impact of the diurnal cycle on longer-term rainfall estimation, estimated diurnal cycles were generated for KWAJ and MELB based on mean hourly conditional mean $(\bar{R} \mid R>0)$ rain rate computed from five years (2000-2004) of radar data. These results are shown in Fig. 3a-b. The filled circles displayed in each profile designate the nominal times when each satellite flies over the site. Fig. $3 \mathrm{~b}$ for MELB reveals a strong diurnal cycle, characterized by its high amplitude maximum in the late afternoon ( $\sim 3 \mathrm{pm} \mathrm{LST})$, and a relative minima occurring between $11 \mathrm{pm}-6 \mathrm{am}$. KWAJ, on the other hand, exhibits a much weaker diurnal cycle, with a nocturnal maximum occurring at around 0100-0200 LST, and a minimum during the daytime hours (Wolff et al., 1995), typical of a tropical oceanic environment.

4.a Probability Distributions by Occurrence and Rain Volume 
This section analyzes the probability distribution functions (PDF) of rain rates for the satellite and co-incident GV data during the study period. Two PDF's were computed for each satellite: (1) PDF by occurrence $\left(\mathrm{PDF}_{\mathrm{c}}\right)$ and $(2) \mathrm{PDF}$ by rain volume $\left(\mathrm{PDF}_{\mathrm{v}}\right)$. The $\mathrm{PDF}_{\mathrm{c}}$ provides statistical information on the breadth and shape of the rain rate distribution and highlights differences in the respective estimate's sensitivity as a function of rain rate. The $\mathrm{PDF}_{\mathrm{v}}$ is a normalized distribution obtained by multiplying the $\mathrm{PDF}_{\mathrm{C}}($ bin) by the rain rate assigned to each bin, and represents the percentage of rain accumulation that each rain rate interval contributes to the total rain volume.

$\mathrm{PDF}_{\mathrm{c}}$ and $\mathrm{PDF}_{\mathrm{v}}$ for KWAJ are shown in Fig. 4. All of the satellite rain rates determined from the GPROF algorithm (AMSR-E, F13, F14, F15 and TMI) exhibit similar PDF $\mathrm{v}_{\mathrm{v}}$ AMSR-E tends to slightly underestimate heavier rain rates, relative to GV. Both TMI and AMSR-E distributions agree quite well, especially in their ability to detect lighter rain rates, which all of the SSM/I and AMSU-B estimates fail to detect. Further the PDFv for SSM/I also show decreased performance in detecting moderate rain rates (above about $0.5 \mathrm{~mm} \mathrm{hr}^{-1}$ ), and a tendency to overestimate the highest rain rates. The AMSU-B rain distributions are highly peaked, around $1 \mathrm{~mm} \mathrm{hr}^{-1}$, which is due to algorithmic "tweaking" of the product by its developers in an effort to increase the sensitivity of the AMSU-B estimates in light rain, which is diminished by the lack of emission channels available on the platforms (R. Ferraro, personal communication, 2008). The result shows a large peak in rates at about $1 \mathrm{~mm} \mathrm{hr}^{-1}$, which we suggest is not physically plausible and should be considered when using AMSU-B data over oceanic areas.

Figures 5a-d show the $\mathrm{PDF}_{\mathrm{c}}$ and $\mathrm{PDF}_{\mathrm{v}}$ for GV and satellite estimates at MELB 
over "Ocean", "Land", "Coast" and "All” terrain types (see Fig. 2c for reference), respectively. Fig. 4a shows the respective PDFs over ocean at MELB. It is obvious that these PDFs are quite similar to the KWAJ PDFs, indicating consistency in our results. Again the AMSR-E distributions are quite similar to the GV estimates, while both SSM/I and AMSU-B estimates tend to under-sample the lightest rain rates. The peaked AMSUB distributions are again evident, at about $1 \mathrm{~mm} \mathrm{hr}^{-1}$, again due to the lack of emission channels for the platform.

Fig. $5 b$ shows the respective PDFs over land areas at MELB. Both TMI and AMSR-E show some diminished performance in detecting the lightest rain rates, relative to GV. At the highest rain rates, the AMSR-E and SSM/I (except F15) all agree fairly well with GV estimates, while TMI slightly overestimates the heaviest rain rates. Not surprisingly, the AMSU-B estimates over land are significantly better than over ocean. Indeed, the AMSU-B estimates are in line with the TMI and AMSR estimates, and somewhat better than the and SSM/I estimates, which is likely due to the additional scattering channels available for the AMSU-B platform. Fig. 5c shows the respective PDFs over coastal areas at MELB. Both TMI and AMSR-E show similar PDFs relative to $\mathrm{GV}$, which is somewhat surprising in that Wolff and Fisher (2008) demonstrated significant differences between the GV and TMI distributions, at the scale of the TMIfootprint (approximately $154 \mathrm{~km}^{2}$ ). The AMSU-B estimates also perform quite well, relative to GV, over coastal areas. Fig. 5d shows the respective PDFs over the entire GV domain at MELB. Once again, the AMSU-B distributions most closely match the GV distributions, and show increased skill in detecting the lighter rain rates. The SSM/I distributions, show a large peak at the more moderate rain rates, not seen in GV, but 
consistent with coastal influences shown previously by Wolff \& Fisher (2008). The AMSU-B estimates over the entire domain perform relatively well, with a strong peak in the distributions introduced by the erroneous ocean-area estimates.

\section{4.b Monthly Mean Rain Rates}

In this section, instantaneous satellite rain rates were validated on monthly scales by computing monthly rainfall estimates using the matched data sets from KWAJ and MELB at $0.25^{\circ}$. The results for KWAJ and MELB are shown in Figures 6 and 7, respectively. The mean monthly rain estimates for KWAJ and MELB show good agreement with measurements made from earth-based and space-based microwave sensors, but there are also some important differences.

In Fig. 6a for KWAJ, all eight satellites are highly correlated with GV month-tomonth and demonstrate good skill at estimating surface rainfall on monthly time scales. However, as displayed in Table 3, all eight satellites show an overall negative bias compared to GV. Similar results are observed in the MELB ocean case shown in Fig. 7a. With the exception of F15 ( $+0.5 \%)$, all of the other sensors exhibited a negative bias. The GV-Satellite comparisons over MELB land exhibit a greater tendency for the satellite sensor to overestimate the rainfall during the summer months. This tendency is especially prevalent in the SSM/I group, which resulted in overall biases ranging between 13.1 and 25.5 percent. Furthermore, the bias exhibits oscillatory behavior, overestimating convective summertime rainfall, while underestimating wintertime rainfall. The MELB Coast case displays similar features as observed in the Land case, with SSM/I exhibiting the highest summertime biases. For MELB Coast, the SSM/I biases ranged from 44.4 to 
71.1.

The AMSU-B sensors showed less consistency as a group. For MELB coast, N15 tends to overestimate summertime rainfall over land and coast, resulting in an overall positive bias in both biases. The N15 bias in the coast case is only $0.5 \%$ because of the tendency for N15 to underestimate surface rainfall during the transition months associated with spring and fall. N17, on the other hand, was negatively biased for both land (-18.3\%) and coast (-42.9). Note that in Fig. 3b, N17 straddles the beginning and end of the convective, characterized by the large amplitude that peaks in the midafternoon.

The results for MELB considered alongside the results for KWAJ illustrate some of the issues over land and coast. and the importance of the lower frequency channels in accurately estimating instantaneous surface precipitation from convective systems. For instance, most of the rainfall budget in Kwajalein is due to convective rainfall, yet the bias remains small, while the sign tended to be negative.

\section{4.c Correlations and Regressions}

Scatter-plots of the various satellite estimates versus GV estimates are shown in Figs. 8 and 9, for KWAJ and MELB, respectively. These plots provide the regression equations and correlations. The slope of each regression equation provides an indication of the relative biases between the various estimates. Fig. 8 shows the scatter-plots for KWAJ. The AMSR-E estimates exhibit the highest correlation of 0.89 , slightly greater than the TMI, which shows a correlation of 0.86 . However, with a slope of 0.79 , the TMI exhibits a slightly lower bias than AMSR-E, which had a slope of 0.75 . The SSM/I and 
AMSU-B correlations are significantly lower, ranging from 0.62 to 0.67 . The slopes of the $\mathrm{SSM} / \mathrm{I}$ range from 0.68 to 0.78 , while the AMSU-B slopes range from 0.49 to 0.65 .

Fig. 9a shows the scatter-plots for MELB over ocean areas only. AMSR-E estimates are better matched with GV estimates with a correlation of 0.86 , and a slope of 0.74 , consistent with our KWAJ results. TMI correlations are 0.84 with a slope of 0.64 . The correlations for the SSM/I rain rates fell within a tight range between $0.66-0.72$, and though lower than TMI and AMSR-E, were significantly greater than the AMSU-B, whose correlations fell within a range between $0.52-0.54$. These results for MELB ocean are again consistent with the results for KWAJ.

Fig. $9 \mathrm{~b}$ shows the scatter-plots for MELB over land areas only. Here, TMI show the highest correlation (0.74) with a slope of 0.86. AMSR-E estimates show a correlation of 0.72 , but with a decreased slope of 0.62 , indicating an increased bias (AMSR-E lower than GV) than over land areas. However, it is important to note that neither SSM/I nor AMSU-B estimates provided significantly improved skill over land areas.

Fig. 9c shows the scatter-plots for MELB over coastal areas only. Although none of the estimates provide correlations greater than 0.74 (TMI), AMSR-E and SSM/I/F15 both have correlations of 0.69 . Somewhat surprisingly, the slopes of the SSM/I regression lines are all near unity (0.91 to 1.05$)$. AMSU-B fares worse than either AMSR-E or SSM/I, with slopes ranging from 0.34 to 0.48 and correlations on the order of 0.5 .

Fig. 9d shows the scatter-plots over the entire GV domain at MELB. TMI shows the highest correlation of 0.74 , with a slope of 0.71 , while AMSR-E shows a correlation 
of 0.72 and a slope of 0.67 . SSM/I estimates show correlations ranging from 0.64 to 0.68 , with slopes ranging from 0.81 to 0.93 . AMSU-B estimates show the lowest correlations, ranging from 0.50 to 0.55 , with slopes ranging from 0.37 to 0.50 .

\section{4d. Rain Rate Profiles}

Mean instantaneous satellite rain rate profiles were constructed for KWAJ and MELB by sorting the satellite rain rates along the $\mathrm{GV}$ rain rate continuum. For this analysis, the matched GV-satellite rain rates were averaged at logarithmic binning intervals between 0 and $12 \mathrm{~mm} \mathrm{hr}^{-1}$ according to the value of the GV rain rate. Wolff and Fisher (2008) previously applied this analysis scheme to the validation of TRMM Level II rain rates. In that study, $\mathrm{GV}$ rain rates were matched to rain rates obtained from the TMI, PR and Combined products at the scale of the TMI footprint. The GV-satellite data were then binned and averaged on a linear scale at $1 \mathrm{~mm} \mathrm{hr}^{-1}$ intervals.

When analyzed on a linear scale the highest rain rates are under-sampled, while the lowest rain rates are over-sampled. The logarithmic scale, applied to this case, has the advantage of naturally partitioning the data into sampling bins of near equal size. The logarithmic scaling provides considerably more resolution at the low end of the spectrum where the sampling was best. How each sensor performs at the low and high ends of the rain rate spectrum are important criteria in evaluating the relative performance and uncertainty of each sensor class. The range of each profile was constrained at $12 \mathrm{~mm} \mathrm{hr}^{-1}$, which represents about $99 \%$ of the total rain volume for each sensor.

The rain rate profiles for all eight satellites are shown in Figs. 10 and 11. For the case of MELB, the matched data was further stratified into ocean, land and coast regimes. 
These are displayed in the four panels shown in Fig. 11. In this evaluation, we examine the members of each sensor class as a group (AMSR, AMSU-B and SSM/I), since each class tends to exhibit structural features characteristic of the instrument and its physical properties.

Looking first at the general characteristics of the different microwave profiles, we observe that all of the rain rate profiles for KWAJ and MELB are well correlated and exhibit good agreement with GV across the nominal mid-range of each plot (i.e., 1 and 10 $\mathrm{mm} \mathrm{hr}^{-1}$ ). The most significant deviations relative to GV occur at the lowest and highest rain rates. The microwave profiles, when considered as a single group, show a distinct tendency to overestimate the low rain rates less than $1.0 \mathrm{~mm} / \mathrm{hr}$ and underestimate the high rain rates greater than $10 \mathrm{~mm} / \mathrm{hr}$. This pattern results in a crossing of the one-to-one line shown in Figs. 10 and 11.

The inter-sensor dispersion is largest for observed rain rates below $1.0 \mathrm{~mm} \mathrm{hr}^{-1}$. This region of the profile approaches the sensitivity threshold of each sensor and its capacity to detect and quantitatively measure light rain rates. At the high end of each profile, we attribute the crossing pattern in each profile to the well-known saturation of the brightness temperatures at high rain rates.

KWAJ is a pure oceanic validation site located in the Central Pacific. For this important case, AMSR-E and the TMI show the best agreement with GV at the lowest rates. Each sensor appears highly correlated down to the lowest rain rates. This observation is reinforced by the PDFs for TMI and AMSR shown in Figs. 4, which also display very impressive agreement with GV at the low rain rates. It should be emphasized, however, that the rain rate profiles are constructed from one-to-one 
matching of the satellite with GV in time and space, whereas the PDFs for the satellite and GV are computed independently.

TMI and AMSR were the only microwave sensors that exhibited a negative total rainfall difference over the four-year period for rain rates less than $1.0 \mathrm{~mm} \mathrm{hr}^{-1}$. From Table 2 it is seen that at KWAJ, TMI and AMSR had $-16.5 \%$ and $-14.0 \%$ biases relative to $\mathrm{GV}$, respectively while in the case of MELB (ocean), the biases were only $-5.3 \%$ for AMSR-E and $-11.3 \%$ for the TMI. Some of these differences between KWAJ and MELB may be attributable to differences in the diurnal cycles of the two regions. MELB exhibits a modified oceanic diurnal cycle, with small maximum amplitude in the late afternoon. TRMM, as noted earlier temporally samples the entire diurnal cycle, while AMSR-E flies over each site twice per day at about the same times as shown in Figs $3 a$ and $3 b$.

SSM/I sensors F13, F14 and F15 also show good agreement with GV for KWAJ. Overall biases for each of the three SSM/I sensors fall within a tight range and exhibit similar features at the low and high end. SSM/I sensors performed even better for the MELB ocean case with biases ranging between 0.5 and -4.0 percent. The AMSU-B sensors N15, N16 and N17, in turn, display properties common to the AMSU-B group, overestimating the rainfall at rain rates less than $1 \mathrm{~mm} \mathrm{hr}^{-1}$ more than the other sensors. This result was expected because the AMSU-B rain rates are inferred based on an ice scattering algorithm that is less correlated with surface rainfall (Spencer 1989). At rain rates greater than $10 \mathrm{~mm} \mathrm{hr}^{-1}$, the $\mathrm{N} 16$ and N17 profiles clearly underestimated the rain rates more than the other sensors, resulting negative biases of -24.5 and -18.4 percent, respectively. The AMSU-B sensors for MELB ocean show more intra-group variance, 
with biases ranging between -28.9 and -13.9 percent.

For MELB, we observe more inter-sensor dispersion in the land and coast cases. Some of this additional variance is attributable to the smaller sample sizes available for each terrain category, but algorithmic uncertainties are also greater due to the dependence of inferred rain rates on passive scattering signatures. For MELB land, inter-sensor biases range from -18.3 for $\mathrm{N} 17$ to 25.5 for F13, and for MELB coast, the satellite biases range from -42.9 to 48.4 . Inter-sensor dispersion is greatest at the low end of the rain rate profile. The land and coast profiles for TMI and AMSR show the best agreement and highest overall correlation with GV. The three AMSU-B sensors reveal the greatest amount of dispersion within the group. In the case of AMSU-B, some of this variability maybe partly ascribed to differences in the diurnal sampling. SSM/I sensors are fairly well correlated with GV over land and coast but tend to exceed GV across most the dynamic range, resulting in land biases of 25.5, 16.0 and 13.1 percent and coast biases of 48.4, 71.1 and 44.4 percent for F13, F14 and F15, respectively.

\section{4.e Two-dimensional Heidke Skill Scores (HSS)}

A common metric used to assess the skill of a given estimate (observation) to measure a predicted rain rate is the Heidke Skill Score (HSS); however, as noted by Connor and Petty (1998), "In this context, HSS only yields information concerning the algorithm's ability to mimic the radar's delineation of the lightest possible surface precipitation-something that radars themselves are not particularly adept at, especially at greater distances (Petty and Katsaros 1992; Kitchen and Jackson 1993). Furthermore, since area coverage by light precipitation is a strong function of threshold rain rate, minor differences in the minimum rain rate detectable by each data source can severely 
degrade the apparent skill of an otherwise robust algorithm. We therefore view HSS as a nearly meaningless measure of algorithm performance when used in this way."

Table 1 shows a generalized $2 \times 2$ contingency table, where in this study, the satellite represents the "Observed" values, while GV estimates serve as the "Predicted"values. The four results illustrate the observed values "Hits", "Misses", "False Alarms", and "Correct Rejections." These values can then be used to compute a number of useful metrics, including: bias, proportion correct, probability of detection, false alarm rates, probability of false detection and other metrics. We use the definition of Connor and Petty (1998), shown in Eq. 3, and follow their lead by constructing multiple contingency tables, using separate rain-rate thresholds for both the validation and the satellite estimates. The resultant array is then contoured to generate the plots shown in Figs. 12-15, for KWAJ and MELB, respectively. For this study, we chose rain rates for both estimates ranging from $0.1-20 \mathrm{~mm} \mathrm{hr}^{-1}$, in increments of $0.1 \mathrm{~mm} \mathrm{hr}^{-1}$.

$$
H S S=\frac{2(A D-B C)}{B^{2}+C^{2}+2 A D+(B+C)(A+D)}
$$

where A, B, C and D are defined in Table 4.

These plots provide significant information regarding the bias and correlation of the two estimates, all as a function of rain rate. If the line of maximum HSS is above/along/below the 1:1 line, then the estimate is high-/non-/low-biased, respectively. Also, the larger the gradient of the HSS values around the line of maximum HSS are, the higher the correlations are.

Fig. 12 shows the Two-Dimensional HSS (HSS2D) for KWAJ for all of the satellite estimates evaluated in this study. TMI and AMSR clearly show the highest skill at all rain rates, with maximum HSS of greater than 0.8 for rain rates up to about $2 \mathrm{~mm}$ 
$\mathrm{hr}^{-1}$, and generally better at all estimates within $0-15 \mathrm{~mm} \mathrm{hr}^{-1}$, although there is a negative bias, which is exacerbated at the higher rain rates, and is also shown in Table 2. TMI shows similar skill as AMSR-E at rain rates below about $5 \mathrm{~mm} \mathrm{~h}^{-1}$. The various SSM/I estimates are similar, but clearly show less skill than the AMSR-E and TRMM estimates. There is a secondary maximum of skill for the SSM/I estimates for rain rates between about $12-20 \mathrm{~mm} \mathrm{hr}^{-1}$. Of the three AMSU-B estimates, N15 and N17 show the greatest skill at KWAJ, while N16 shows the least skill, and strong bias above about $4 \mathrm{~mm} \mathrm{hr}^{-1}$, illustrated by the axis of maximum HSS below the 1:1 line.

Figure 13 shows, for each validation rain rate, the maximum HSS at KWAJ, again illustrating that AMSR-E shows the best skill at all rain rates, followed by TMI, SSM/I and AMSU. The maximum HSS values TMI and AMSR are about 0.2 higher than all other estimates, for all rain rates up to about $15 \mathrm{~mm} \mathrm{hr}^{-1}$. The SSM/I skills are in general higher than the AMSU-B skills by about 0.1 , with some increased skill of about +0.2 (relative to AMSU) for rain rates greater than $10 \mathrm{~mm} \mathrm{hr}^{-1}$. Connor and Petty (1998) noted that these types of plots make it possible to evaluate and objectively inter-compare, the maximum potential skill of competing algorithms, irrespective of algorithm calibration differences. Further, they correctly state that there is no built-in assumption of linearity in the relationship between the satellite estimate and the validation data, as would be inferred from simple scatter-plots.

Fig. 14a shows the HSS2D for MELB over ocean areas only. Once again, the TMI and AMSR skills are quite high, with maximum HSS values of about 0.8 in the $1-2 \mathrm{~mm}$ $\mathrm{hr}^{-1}$ range. Also, there is a clear negative bias in both TMI and AMSR estimates, which is exacerbated at rain rates greater than $10 \mathrm{~mm} \mathrm{hr}^{-1}$. Although the biases of the SSM/I 
estimates tend to be smaller than the AMSR-E biases, their skills are lower. AMSU-B shows the lowest skill, again, over ocean areas at MELB, with little or no skill in observing rain rates beyond about $10 \mathrm{~mm} \mathrm{hr}^{-1}$.

Over land, shown in Fig. 14b, the AMSR-E skills are not as high as over ocean, but the biases are more near unity. TMI actually shows slight increase in skill, relative to AMSR-E. The SSM/I shows slightly lower skills than AMSR-E, but biases are near zero for rain rates less than $10 \mathrm{~mm} \mathrm{hr}^{-1}$. AMSU-B shows the lowest skills at all rain rates, with a negative bias (i.e. AMSU-B less than GV). Over coast, the AMSR-E and SSM/I estimates show skills on the order of 0.5 to 0.8 for rain rates less than $10-15 \mathrm{~mm} \mathrm{hr}^{-1}$; however, the AMSR-E estimates are negatively biased, while all of the SSM/I estimates are negatively biased. Given that AMSR-E, TMI and SSM/I all use the GPROF algorithm, we are not sure how to assess the discrepancy between their performance over coastal areas, but suggest that algorithm developers investigate possible reasons and incorporate the apparent improvements into their algorithms. Finally, over the entire GV domain at MELB, shown in Fig. 14d, AMSR-E shows the highest skills, with a slight negative bias, while SSM/I show somewhat reduced skill, but either near-unity or slightly positive biases, and AMSU-B show the lowest skill and are strongly negatively biased. Figure 15 shows the maximum HSS for each validation rain bin. Over ocean, both TMI and AMSR show significantly better skill, at all rain rates than SSM/I and AMSU-B estimates. Over land, differences between the HSS maxima between AMSR-E, TMI and other estimates is not as large, but still show increased skills over all, except the highest rain rates, where $\mathrm{F} 15$ show some increased skill at rain rates greater than $17 \mathrm{~mm} \mathrm{hr}^{-1}$.

\section{Summary and Conclusions}


In this study, four years (2003-2006) of instantaneous radar rain estimates obtained from Tropical Rainfall Measuring Mission (TRMM) Ground Validation (GV) sites at Kwajalein, Republic of the Marshall Islands (KWAJ) and Melbourne, Florida (MELB) were used to assess the relative performance of satellite precipitation estimates from seven polar-orbiting satellites and the TMI on board TRMM. Instantaneous rain rates derived from each microwave sensor on board the different satellites were matched to the $\mathrm{GV}$ estimates in time and space at a resolution of 0.25 degrees. The study evaluates the measurement and error characteristics of the various satellite estimates through intercomparisons with GV radar estimates. The GV rain observations provided an empirical ground-based reference for assessing the relative performance of each sensor and sensor class.

All eight satellites compared well with GV at KWAJ and MELB when intercompared on monthly scales, especially over the ocean where all of the available rain information was utilized. The microwave sensors were more prone to overestimates over land and coast, and not unexpectedly, they performed the worst in the case of MELB coast. AMSR-E and the TMI generally performed the best over all of terrain types, though their biases over the ocean were commensurate with the other satellites. TMI and AMSR also showed the best correlation with GV and displayed the highest skills in observing GV rain rates over the full dynamic range of the observations. Table 2 illustrates that over ocean at KWAJ, all of the satellite estimates showed negative biases on the order of $-10 \%$ to $-25 \%$.

Table 3 revealed that over ocean areas at MELB, the biases were also generally negative, ranging from $+0.5 \%(\mathrm{~F} 15)$ to $-29 \%(\mathrm{~N} 17)$. Over land at MELB, there was 
considerable more spread in the sign and magnitude of the biases, with a $+25.5 \%$ positive bias for F13, and $-18 \%$ bias for N17. Also, over land at MELB, AMSR-E displayed a very small bias of $-1.2 \%$, while TMI showed a positive bias of $12.2 \%$. We infer that the differences in these biases are due to the following: 1) the TRMM orbit allows a full sample of the diurnal cycle, especially over the large temporal scales employed in this study; 2) minor variations in the instrumentation of the different platforms; and 3) variations in the algorithms used to retrieve the rain rates, often referred to as "versionitis."

Over coastal areas at MELB (Table 3), there was considerable deviation in the biases, with SSM/I showing large positive biases ranging from $+44 \%$ to $+71 \%$, as well the rather inconsistent AMSU-B estimates, which range from $-43 \%$ to $+0.5 \%$. TMI and AMSR-E both showed relative small negative biases of $-12.9 \%$ and $-8.2 \%$, respectively. Looking at the entire domain, irrespective of the terrain type, the biases range from $31.8 \%$ (N17) to $+33.5 \%$ (F14), with TMI and AMSR showing remarkably small biases of $-4.2 \%$ and $-5.5 \%$.

It is important to note that assessing the biases alone is not sufficient to determine which satellite estimates fare best, especially since the GV estimates themselves may incur some bias. Further, a simple comparison of the PDFs can also be misleading, because the information relating to the time-space matching is lost in the statistical construction of the PDF. Hence, analysis of scatter-plots, simple statistics, and the two dimensional skill scores, as was done in this study, is needed to provide a more complete picture of how a satellite estimate is performing, especially with respect to the observation (i.e. detection) surface precipitation from space. 
The rain rate profiles generated in Figs. 10 and 11 revealed that only TMI and AMSR-E performed well in estimating GV rain rates less than $1.0 \mathrm{~mm} \mathrm{hr}^{-1}$, while the other satellites tended to overestimate the rain rates in this region. This result is important because the sampling was extremely high in that region of each profile. Two of the AMSU-B estimates (N15 and N16) performed the worst in overestimating the low rain rates, while N17 underestimated the high rain rates by more the any of the other satellites. It is noteworthy that over land and coast there was more overall dispersion between the different satellites. The profiles for each sensor group, nonetheless, tended to display similar characteristics.

Probability distributions for the various satellites indicate that both TMI and AMSR-E are significantly better, and more highly correlated with GV estimates than the SSM/I retrievals, and to a larger extent the AMSU-B estimates. Artificial "tweaking" of the AMSU-B estimates of light rain rates (approximately $1 \mathrm{~mm} \mathrm{hr}^{-1}$ ) over ocean, in particular, provides for physically implausible distributions, and caution should be taken when these data are used. Two-dimensional Heidke Skill Score plots show also that both TMI and AMSR-E are significantly better skilled at detecting surface precipitation, providing less biased, more highly correlated, and more linear comparisons than SSM/I and significantly more so than AMSU-B estimates, especially over ocean. Over land areas, the differences between the skills of the various estimates is smaller, but we find that the TMI estimates be superior, followed by AMSR-E, SSM/I and AMSU-B.

These results signal developers of global rainfall products, such as the TRMM Multi-Satellite Precipitation Analysis (TMPA), that care must be taken when incorporating data from these input satellite estimates in order to provide the highest 
quality estimates when attempting to merge the data from external sources. For example, as is currently done with the TMPA product, if two or more estimates are available in a given 3-hour, $0.25^{\circ}$ grid, the two estimates would be averaged. We would suggest instead that the contributions be weighted by quality in order to provide the most robust estimates.

\section{Acknowledgements}

NASA Grant NNG07EJ50C funded this study. The authors would like to thank Dr. Ramesh Kakar (NASA Headquarters), Dr. Scott Braun (TRMM Project Scientist), Dr. Arthur Hou (GPM Project Scientist), and Mr. Richard Lawrence (Chief, TRMM Satellite Validation Office) for their support of this effort. We would also like to thank the support staff of the TRMM Ground Validation program at NASA GSFC, especially David Marks, David Silberstein and Jason Pippitt, and David Makofski. 


\section{REFERENCES}

Adler, R. F., G. J. Huffman, and P. R. Keehn, 1994: Global tropical rain estimates from microwave-adjusted geosynchronous IR data. Remote Sens. Rev., 11, 125-152. Allam,

R., G. Holpin, P. Jackson, and G.-L. Liberti, 1993: Second Algorithm Intercomparison Project of the Global Precipitation Climatology Project: AIP-2. Pre-Workshop Report, $133 \mathrm{pp}$. [Available from Satellite Image Applications Group, UKMO, Bracknell, Berkshire, United Kingdom.].

Arkin, P. A., 1979: The relationship between fractional coverage of high cloud and rainfall accumulations during GATE over the B-scale array. Mon. Wea. Rev., 107, 1382-1387.

Arkin, P. A., and B. Meisner, 1987: The relationship between large-scale convective rainfall and cold cloud over the Western Hemisphere during 1982-1984. Mon. Wea. Rev., 115, 51-74.

Bell, T. L., and N. Reid, 1993: Detecting the diurnal cycle of rainfall using satellite observations. J. Appl. Meteor. 32, 311-322..

Berg, W., T. L'Ecuyer, and C. Kummerow, 2006: Rainfall climate regimes: The relationship of regional TRMM rainfall biases to the environment. J. Climate Appl. Meteor., 45, 434-454.

Chen, F. W., and D. H. Staelin, 2003: AIRS/AMSU/HSB precipitation estimates. IEEE Transactions on Geoscience and Remote Sensing, 41, 410-417.

Conner, M. D., and G. W. Petty, 1998: Validation and intercomparison of SSM/I rain-rate retrieval methods over the continental United States. J. Appl. Meteor., 37, 679-700. 27

Ebert, E. E., and M. J. Manton, 1998: Performance of satellite rainfall estimation algorithms during TOGA-COARE. J. Atmos. Sci., 55, 1537-1557.

Ebert, E. E., M. J. Manton, P. A. Arkin, R. J. Allam, G. E. Holpin, and A. Gruber, 1996: Results from the GPCP Algorithm Intercomparison Programe. Bull. Ams. Soc., 77, 2875-2887.

Ferraro R. R., and G. F. Marks, 1995: The development of SSM/I rain-rate retrieval algorithms using ground-based radar measurements. . J. Atmos. Ocean. Tech, 12, 755770 .

Ferraro, R. R., 1997: Special sensor microwave imager derived global rainfall estimates for climatological applications. J. Geo. Res., Vol. 102, No. D14, 16715-16735. 
Ferraro, R. R., E. A. Smith, W. Berg, and G. J. Huffman, 1998: A screening methodology for passive microwave precipitation retrieval algorithms. J. Atmos. Sci., 55, 15831600 .

Ferraro, R. R., F. Weng, N. C. Grody, L. Zhao, 2000: Precipitation characteristics over land from the NOAA-15 AMSU-B sensor. Geophysical Research Letters, 27, 26692672.

Ferraro, R. R., F. Weng, N. C. Grody, L. Zhao, H. Meng, C. Kongoli, P Pellegrino, S. Qiu, and C. Dean, 2005: NOAA operational hydrological products derived from the advanced microwave sounding unit. IEEE Transactions on Geoscience and Remote Sensing, 43, 1036- 1049.

Griffith, C. G., W. L. Woodley, P. G. Grube, D. W. Martin, J. Stout, and D. N. Sikdar, 1978: Rain estimation from geosynchronous satellite imagery-visible and infrared studies. Mon. Wea. Rev., 106, 1153-1171.

Grody, N. C., 1991: Classification of snow cover and precipitation using the Special Sensor Microwave/Imager (SSM/I). J. Geophys. Res., 96, 7423-7435.

Hong, Y., T. T. Wilheit, W. R. Russell, 1997: Estimation of monthly rainfall over oceans from truncated rain-rate samples: Application to SSM/I data. J. Atmos. and Ocean. Tech., 14, 1012-1022.

Hou, A. Y., et al, 2007: The Global Precipitation Measurement (GPM) Mission. Bull. Amer. Meteor. Soc., in preparation.

Hsu, K., X. Gao, S. Sorooshian, and H.V. Gupta, 1997: Precipitation estimation from remotely sensed information using artificial neural networks, Journal of Applied Meteorology, Vol. 36, pp.1176-1190.

Huffman, G. J., 1997: Estimates of root-mean-square random error for finite samples of estimated precipitation. J. Appl. Met.,36, 1191-1201.

Huffman, G. J., R. F. Adler, D. T. Bolvin, G. Gu, E. J. Nelkin, K. P. Bowman, Y. Yong, E. F. Stocker, and D. B. Wolff (2007), The TRMM Multi-satellite Precipitation Analysis (TMPA): Quasi-global, multi-year, combined-sensor precipitation at fine scales, J. Hydro. Met., 8, 38-55.

Iguchi, T., T. Kozu, R. Meneghini, J. Awaka, K. Okamoto, 2000: Rain-profiling algorithm for the TRMM precipitation radar. J. Appl. Met., 39, 2038-2052.

Johnson, R. H., T. M. Rickenbach, S. A. Rutledge, P. E.. Ciesielski, and W. H. Schubert, 1999: J. Clim., 12, 2397-2418. 
Joyce, R. J., J. E. Janowiak, P. A. Arkin, and P. Xie, 2004: CMORPH: A method that produces global precipitation estimates from passive microwave and infrared data at high spatial and temporal resolution. J. Hydrometeor., 5, 487-503.

Kidd, C. K., D. R. Kniveton, M. C. Todd, and T. J. Bellerby, 2003: Satellite rainfall estimation using combined passive microwave and infrared algorithms. $J$.

Hydrometeor., 4, 1088-1104.

Kilonsky, B. J., and C. S. Ramage, 1976: A technique for estimating tropical open-ocean rainfall from satellite observations. J. Appl. Meteor., 15, 972-975.

Kummerow, C., and L. Giglio, 1994: A passive microwave technique for estimating rainfall and vertical structure information from space. Part II: applications to SSM/I data. J. Appl. Meteor., 33, 19-34.

Kummerow, C., W. S. Olson, and L. Giglio, 1996: A simplified scheme for obtaining precipitation and vertical hydrometeor profiles from passive microwave sensors. IEEE Trans. Geosci. Remote Sens., 34, 1213-1232.

Kummerow, C., W. Barnes, T. Kozu, J. Shiue, and J. Simpson, 1998: The Tropical Rainfall Measuring Mission (TRMM) sensor package. J. Atmos. Ocean. Tech., 15, 809-817.

Kummerow, C. , and Coauthors, 2000: The status of the tropical Rainfall Measuring Mission (TRMM) after two years in orbit. J. Appl. Meteor., 39, 1965-1982.

Kummerow, C., Y. Hong, W. S. Olson, S. Yang, R. F. Adler, J. McCollum, R. Ferraro, G. Petty, D.-B. Shin, and T. T. Wilheit, 2001: The evolution of the Goddard profiling algorithm 29 (GPROF) for rainfall estimation from passive microwave sensors. $J$. Appl. Meteor., 40, 1801- 1820.

Lau, K. M., and H. T. Wu, 2003: Warm rain processes over tropical oceans and climate implications. Geo. Research Letters, 30, 2290.

Liao, L., R. Meneghini, and T. Iguchi, 2001: Comparisons of rain rate and reflectivity factor derived from the TRMM precipitation radar and the WSR-88D over the Melbourne, Florida, site. Jou. Atmos. and Ocean. Tech., 18, 1959-1974.

Lin, Xin, and A. Y. Hou: Evaluation of Coincident Passive Microwave Rainfall Estimates Using TRMM PR and Ground Measurements as References. J. Climate Appl. Meteor. (in press).

Lin, Xin, L. D. Fowler, and D. A. Ranfall, 2002: Flying the TRMM satellite in a general circulation model. J. Geophys. Res., 107 (D16), Art. No. 4281.

Lin, Y., and K. E. Michell, 2005: The NCEP Stage II/IV hourly precipitation analyses: development and application. Preprints, 19th Conf. On Hydrology, American 
Meteorological Society, San Diego, CA, 9-13 January 2005, P. 1-2.

Liu, G., and J. A. Curry, 1992: Retrieval of precipitation from satellite microwave measurement using both emission and scattering. J. Geophys. Res., 97, 9959-9974.

Marks, D. A., D. B. Wolff, D. S. Silberstein, A. Tokay, J. L. Pippitt, and J. Wang, 2008: Availability of a High Quality TRMM Ground Validation Data at Kwajalein, RMI: A Practical Application of the Relative Calibration Adjustment Technique: J. Atmos. Ocean. Tech., (accepted).

Masunaga, H., T. Iguchi, R. Oki, and M. Kachi. 2002: Comparison of Rainfall Products Derived from TRMM Microwave Imager and Precipitation Radar. Jou. Appl. Meteor.: 41, 849-862.

McCollum J. R., and R. R. Ferraro, 2003: Next general of NOAA/NESDIS TMI, SSM/I, and AMSR-E microwave land rainfall algorithms. J. Geo. Res., Vol. 108, No. D8, 2001JD001512.

McCollum J. R., and R. R. Ferraro, 2005: Microwave rainfall estimation over coasts. $J$. Atmos. Ocean. Tech, 22, 497-512.

Meneghini, R., and T. Kozu, 1990: Spaceborne Weather Radar. Artech House, Boston, 197 pages.

Nesbitt, S. W., E. J. Zipser, and C. Kummerow, 2004: An examination of version-5 rainfall estimates from the TRMM Microwave Imager, precipitation radar, and rain gauge on global, regional, and storm scales. J. Appl. Meteor., 43, 1016-1036.

Olson, W., C. Kummerow, G. M. Heymsfield, and L. Giglio, 1996: A method for combined passive-active microwave retrievals of cloud and precipitation profiles. $J$. Appl. Meteor, 35, 1763-1789. 30

Olson, W. S., C. Kummerow, Y. Hong, and W.-K. Tao, 1999: Atmospheric latent heating distributions in the Tropics derived from satellite microwave radiometer measurements. J. Appl. Meteor., 38, 633-664.

Olson, W. S. C. D. Kummerow, S. Yang, G. W. Petty, W.-K. Tao, T. L. Bell, S. A. Braun, Y. Wang, S. E. Lang, D. E. Johnson, and C. Chiu, 2006: Precipitation and latent heating distributions from satellite passive microwave radiometry. Part I: Improved method and uncertainties. J. Climate Appl. Meteor., 45, 702-720.

Petty, G. W., 1994a: Physical retrievals of over-ocean rain rate from multichannel microwave imaging. Part I: Theoretical characteristics of normalized polarization and scattering indices. Meteor. Atmos. Phys., 54, 79-100..

Petty, G. W., 1994b: Physical retrievals of over-ocean rain rate from multichannel microwave imaging. Part II: Algorithm implementation. Meteor. Atmos. Phys., 54, 
$101-122$.

Petty, G. W., 1995: Frequencies and characteristics of global oceanic precipitation from shipboard present-weather reports. Bull. Amer. Meteor. Soc., 76, 1593-1616.

Petty, G. W., 1999: Prevalence of precipitation from warm-topped clouds over eastern Asia and the Western Pacific. J. Clim., 12, 220-229.

Prabhakara, C., G. Dalu, G. L. Liberti, J. J. Nucciarone, and R. Suhasini, 1992: Rainfall estimation over oceans from SSMR and SSM/I microwave data, J. Appl. Meteor., 31, 532-552.

Schumacher, C., and R. A. Houze, 2000: Comparison of radar data from the TRMM satellite and Kwajalein oceanic validation site. J. Appl. Meteor., 39, 2151-2164.

Silberstein, D. S., D. B. Wolff, D. A. Marks, D. Atlas and J. L. Pippitt, 2007: Ground Clutter as a Monitor of Radar Stability at Kwajalein, RMI. J. Atmos. Ocean. Tech. (in press).

Simpson, J., R. F. Adler, and G. R. North, 1988: Proposed tropical rainfall measuring mission (TRMM) satellite. Bull. Amer. Meteor. Soc., 69, 278-295.

Simpson, J., C. Kummerow, W.-K. Tao, and R. F. Adler, 1996: On the Tropical Rainfall Measuring Mission (TRMM). Meteorol. Atmos. Phys., 60, 19-36. 31

Smith, E. A., X. Xiang, A. Mugnai, and G. J. Tripoli, 1994a: Design of an inversionbased precipitation profile retrieval algorithm using an explicit cloud model for initial guess microphysics. Meteorol. Atmos. Phys., 54, 53-78.

Smith, E. A., C. Kummerow, and A. Mugnai, 1994b: The emergence of inversion-type precipitation profile algorithms for estimation of precipitation from satellite microwave measurements. Remote Sensing Reviews, 11, 211-242.

Smith, E. A., X. Xiang, A. Mugnai, R. Hood, and R. W. Spencer, 1994c: Behavior of an inversion-based precipitation retrieval algorithm with high resolution AMPR measurements including a low frequency $10.7 \mathrm{Ghz}$ channel. J. Atmos. Ocean. Tech., 11, 858-873.

Smith, E. A., and co-authors, 1998: Results of WetNet PIP-2 Project. J. Atmos. Sci., 55, $1483-1536$.

Spencer, R. W., W. S. Olson, W. Rongzhang, D. W. Martin, J. A. Weinman, and D. A. Santek, 1983: Heavy thunderstorms observed over land by the Nimbus 7 Scanning Multichannel Microwave Radiometer. J. Climate Appl. Meteor., 22, 1041-1046.

Spencer, R. W., 1986: A satellite passive 37-GHz scattering-based method for measuring 
oceanic rain rates $J$. Climate Appl. Meteor., 25, 754-766.

Spencer, R. W., H. M. Goodman, and R. E. Hood, 1989: Precipitation retrieval over land and ocean with the SSM/I. Part I: Identification and characteristics of the scattering signal. J. Atmos. Ocean. Tech., 6, 254-273.

Vila, D.,R.Ferraro, R. Joyce, 2007: Evaluation and improvement of AMSU-B precipitation retrievals. JGR, 112, D20119, doi:10:1029/2007JD008617.

Wienman, J. A., and P. J. Guetter, 1977: Determination of rainfall from microwave radiation measured by Nimbus 6 ESMR. J. Appl. Meteor., 16, 437-442.

Weng, F., L. Zhao, R. Ferraro, G. Poe, X. Li, and N. Grody, 2003: Advanced Microwave Sounding Unit cloud and precipitation algorithms. Radio Sci., 38, 8068-8079. 32

Wilheit T. T., A. T. C. Chang, S. C. V. Rao, E. B. Rodgers, and J. S. Theon, 1977: A satellite technique for quantitatively mapping rainfall rates over the oceans. J. Appl. Meteor., 16, 551- 560.

Wilheit, T. T., 1986: Some comments on passive microwave measurement of rain. Bull. Amer. Meteor. Soc., 67, 1226-1232.

Wolff, D. B., D. A. Marks, E. Amitai, D. S. Silberstein, B. L. Fisher, A. Tokay, J. Wang, and J. L. Pippitt, 2004: Ground validation for the Tropical Rainfall Measuring Mission. J. Atmos. Ocean. Tech, 22, No. 4, 365-380.

Wolff, D. B. and B. L. Fisher, 2008: Comparisons of Instantaneous TRMM Ground Validation and Satellite Rain Rate Estimates at Different Spatial Scales. $J$. Climate Appl. Meteor. (in press).

Yang, S., W. S. Olson, J.-J. Wang, T. L. Bell, E. A. Smith, and C. D. Kummerow, 2006: Precipitation and latend heating distributions from satellite passive microwave radiometry. Part II: Evaluation of estimates using independent data. J. Climate Appl. Meteor., 45, 721-739.

Zhao, L., and F. Weng, 2002: Retrieval of ice cloud parameters using the Advanced Microwave Sounding Unit. J. Appl. Meteor., 41, 384-395. 
Table 1. : List of available frequencies $(\boldsymbol{v})$ and polarizations $(\boldsymbol{\sigma})$ of the various satellites assessed in this study. $V$ and $H$ represent vertical and horizontal polarizations, respectively. Column 1 provides the name of the satellite platform

Table 2: General statistics derived from the period 2003-2006, showing comparisons between TRMM GV estimates at KWAJ versus the various satellites estimates assessed in this study. The columns, from left to right, correspond to site, satellite, GV mean rain rate $\left(\mathrm{mm} \mathrm{hr}^{-1}\right)$, satellite mean rain rate $\left(\mathrm{mm} \mathrm{hr}^{-1}\right)$, regression equation intercept and slope, correlation, and bias. The bias, expressed in percentage is defined via the following: Bias $=100 \% *\left(\right.$ Sat_mean $-G V \_$mean $) / G V$ mean, so that a negative bias indicates a satellite underestimate, relative to $G V$.

Table 3: Same as Table 2, except for MELB. Also, the statistics are sub-classified by terrain type (Ocean, Land, Coast and All).

Table 4: Contingency table construction used for calculating the Heidke Skill Score and other metrics. In our study, satellite estimates are "Observed", while validation estimates are "Predicted." 


\section{LIST OF FIGURES}

Fig. Ia: Illustration of the gauge and radar networks for the GV network at KWAJ. Range rings at 50,100, 150 and $200 \mathrm{~km}$ are also shown. Note that for this study, all usable GV data was restricted to the first $100 \mathrm{~km}$ from each respective radar site. $K W A J$ has only seven gauge sites; however, each site contains two or more gauges to improve reliability and uncertainty of the measured rain rates.

Fig. 1b: Same as Fig. 1a, except for MELB. There are three gauge networks in Florida: St. John's River Water Management District (STJ), and the South Florida Water Management District (SFL). Both of these networks are operated by the state of Florida. A NASA-owned network is located on Cape Canaveral at NASA Kennedy Space Center.

Fig. 2a: Terrain masks for the KWAJ GV site. Each $0.25^{\circ}$ grid box is designated as ocean (3), land (0), coastal-water (4), or coastal land (5). Both coastal-land and coastal-water are treated together as "coast" in this study. The respective GV radar is located at the center of each image and range rings at $50 \mathrm{~km}, 100 \mathrm{~km}$ and $150 \mathrm{~km}$ are also shown.

Fig. 2b: Same as Fig. 2a, except for MELB

Fig. 3a: Diurnal cycle of hourly conditional mean rain rate, derived from seven years (2000-2006) of GV data at HSTN. Superimposed are colored symbols showing the local overpass times of each of the polar-orbiting satellites assessed in this study. 
Fig. 3b: Same as Fig. 2a, except for MELB.

Fig. 4: Probability density functions (PDF) of rain rates for TRMM GV and the various satellite retrievals at KWAJ. The dashed and dotted lines represent the PDF by occurrence $P D F_{c}=P D F(R)$ for $G V$ and satellite, respectively, while the solid and dashdotted lines represent the PDF by volume $P D F_{v}=\left[R^{*} P D F(R)\right]$ for $G V$ and Satellite, respectively.

Fig.5a: Probability density functions (PDF) of rain rates for TRMM GV and the various satellite retrievals at MELB over ocean areas only. The dashed and dotted lines represent the $P D F$ by occurrence $P D F_{c}=(P D F(R)]$ for $G V$ and satellite respectively, while the solid and dash-dotted line represent the PDF by volume $P D F_{v}=[R * P D F(R)]$.

Fig 5b: Same as Fig. 5a, except over land areas only at MELB.

Fig. 5c: Same as Fig. 5a, except for coastal areas only at MELB.

Fig. 5d: Same as Fig. 5a, except for the entire GV domain at MELB.

Fig. 6: Monthly rain computed estimates for KWAJ for each of the seven space-borne microwave estimates. Rain estimates only integrated matched $G V$-satellite rain rates during satellite overpasses. 
Fig. 7a: Same as Fig. 6, except for over ocean areas at MELB.

Fig. 7b: Same as Fig. 6, except for over land areas only at MELB.

Fig. 7c: Same as Fig. 6, except for over coastal areas only at MELB.

Fig. 7d: Same as Fig. 6, except for over the entire GV domain at MELB.

Fig 8: Scatter plots of instantaneous satellite and GV rain rates for KWAJ/Ocean for the period 2003-2006.

Fig 9a: Scatter plots of instantaneous satellite and GV rain rates for MELB over ocean areas only, for the period 2003-2006.

Fig 9b: Same as Fig. 9a but over land areas only.

Fig 9c: Same as Fig. 9a but over coastal areas only.

Fig. 9d: Same as Fig. 9a, but over the entire GV domain at MELB.

Fig. 10: Rain rate profiles for AMSR, F13, F14, F15, N15, N16 and N17 generated for KWAJ using GV as an empirical reference. Satellite rain rates were binned and sorted 
along the $G V$ rain rate continuum.

Fig. 11: Rain rate profiles for AMSR, F13, F14, F15, N15, N16 and N17 generated from matched $G V$-satellite data set for MELB using $G V$ as an empirical reference. Satellite rain rates were binned and sorted along the GV rain rate continuum. The matched data was further stratified according to Ocean (top left), Land (top right), Coast (bottom left) and All (bottom right).

Fig. 12: Two-dimensional Heidke Skill Score plots for the various satellite and GV estimates. The line through the contours represents the maximum HSS for a given GV rain rate.

Fig. 13: Maximum Heidke Skill Scores for a given GV rain rate at KWAJ for each of the various satellites. Line colors specify the particular satellite estimate.

Fig. 14a: Same as Fig. 12, except over ocean areas at MELB.

Fig. 14b: Same as Fig. 12, except for land areas over MELB.

Fig. 14c: Same as Fig. 12, except for coastal areas over MELB.

Fig. 14d: Same as Fig. 12, except for the entire GV domain over MELB. 
Fig 15: Maximum Heidke Skill Score for a given GV rain rate at MELB for the various satellites. The panels show these scores over "Ocean", "Land", "Coast" and "All" in the top-left, top-right, bottom-left and bottom-right panels, respectively. 
Table 1. : List of available frequencies $(\boldsymbol{v})$ and polarizations $(\boldsymbol{\sigma})$ of the various satellites assessed in this study. $V$ and $H$ represent vertical and horizontal polarizations, respectively. Column 1 provides the name of the satellite platform.

\begin{tabular}{|c|c|c|c|c|c|c|c|c|c|c|c|c|c|}
\hline \multirow[t]{2}{*}{ Sensor } & \multirow{2}{*}{$\begin{array}{l}\text { Para } \\
\text { mete } \\
\text { r }\end{array}$} & \multicolumn{12}{|c|}{ Channels (GHz) } \\
\hline & & 1 & 2 & 3 & 4 & 5 & 6 & 7 & 8 & 9 & 10 & 11 & 12 \\
\hline \multirow{2}{*}{$\begin{array}{c}\text { AMSR- } \\
\text { E }\end{array}$} & $v$ & 6.9 & 6.9 & 10.7 & 10.7 & 18.7 & 18.7 & 23.8 & 23.8 & 36.5 & 36.5 & 89.0 & 89.0 \\
\hline & $\sigma$ & $\mathrm{V}$ & $\mathrm{H}$ & $\mathrm{V}$ & $\mathrm{H}$ & $\mathrm{V}$ & $\mathrm{H}$ & $\mathrm{V}$ & $\mathrm{H}$ & $\mathrm{V}$ & $\mathrm{H}$ & $\mathrm{V}$ & $\mathrm{H}$ \\
\hline \multirow{2}{*}{ SSM/I } & $v$ & 19.35 & 19.35 & 22.3 & 37.0 & 37.0 & 85.5 & 85.5 & & & & & \\
\hline & $\sigma$ & $\mathrm{V}$ & $\mathrm{H}$ & $\mathrm{V}$ & $\mathrm{V}$ & $\mathrm{H}$ & $\mathrm{V}$ & $\mathrm{H}$ & & & & & \\
\hline \multirow{2}{*}{$\begin{array}{c}\text { AMSU- } \\
\text { A,B* }\end{array}$} & $v$ & 23.8 & 31.4 & 36.5 & 89.9 & 150 & $183.3^{1}$ & $183.3^{2}$ & $183.3^{3}$ & & & & \\
\hline & $\sigma$ & $\mathrm{V}$ & $\mathrm{V}$ & $\mathrm{V}$ & $\mathrm{V}$ & $\mathrm{V}$ & $\mathrm{V}$ & $\mathrm{V}$ & $\mathrm{V}$ & & & & \\
\hline \multirow[b]{2}{*}{ TMI } & $v$ & 10.7 & 10.7 & 19.35 & 19.35 & 21.3 & 37.0 & 37.0 & 85.5 & 85.5 & & & \\
\hline & $\sigma$ & $\mathrm{V}$ & $\mathrm{H}$ & $\mathrm{V}$ & $\mathrm{H}$ & $\mathrm{V}$ & $\mathrm{V}$ & $\mathrm{H}$ & $\mathrm{V}$ & $\mathrm{H}$ & & & \\
\hline
\end{tabular}

*AMSU-B channels at $89.9,150$, and $183 \mathrm{GHz}$ correspond to channels numbers $16-20$

1. $183.3 \pm 1.00 \mathrm{GHz}$;

2. $183.3 \pm 3.00 \mathrm{GHz}$;

3. $183.3 \pm 7.00 \mathrm{GHz}$ 
Table 2: General statistics derived from the period 2003-2006, showing comparisons between TRMM GV estimates at KWAJ versus the various satellites estimates assessed in this study. The columns, from left to right, correspond to site, satellite, GV mean rain rate $\left(\mathrm{mm} \mathrm{hr}^{-1}\right)$, satellite mean rain rate $\left(\mathrm{mm} \mathrm{hr}^{-1}\right)$, regression equation intercept and slope, correlation, and bias. The bias, expressed in percentage is defined via the following: Bias $=100 \% *($ Sat_mean $-G V$ mean $) / G V$ mean, so that a negative bias indicates a satellite underestimate, relative to $G V$.

\begin{tabular}{|c|c|c|c|c|c|c|c|}
\hline Site & Sat & Mask & $\begin{array}{c}\text { GV } \\
\text { Mean }\end{array}$ & $\begin{array}{c}\text { Sat } \\
\text { Mean }\end{array}$ & Slope & Corr & Bias \\
\hline KWAJ & F13 & Ocean & 0.231 & 0.196 & 0.74 & 0.67 & -15.0 \\
\hline KWAJ & F14 & Ocean & 0.238 & 0.205 & 0.78 & 0.67 & -13.9 \\
\hline KWAJ & F15 & Ocean & 0.232 & 0.203 & 0.68 & 0.63 & -12.5 \\
\hline KWAJ & N15 & Ocean & 0.241 & 0.21 & 0.65 & 0.66 & -12.8 \\
\hline KWAJ & N16 & Ocean & 0.266 & 0.201 & 0.49 & 0.62 & -24.5 \\
\hline KWAJ & N17 & Ocean & 0.242 & 0.198 & 0.57 & 0.65 & -18.4 \\
\hline KWAJ & AMSR & Ocean & 0.231 & 0.193 & 0.75 & 0.89 & -16.5 \\
\hline KWAJ & TMI & Ocean & 0.245 & 0.211 & 0.79 & 0.86 & -14.0 \\
\hline
\end{tabular}


Table 3: Same as Table 2, except for MELB. Also, the statistics are sub-classified by terrain type (Ocean, Land, Coast and All).

\begin{tabular}{|c|c|c|c|c|c|c|c|}
\hline Site & Sat & Mask & $\begin{array}{c}\text { GV } \\
\text { Mean }\end{array}$ & $\begin{array}{c}\text { Sat } \\
\text { Mean }\end{array}$ & Slope & Corr & Bias \\
\hline MELB & F13 & Ocean & 0.123 & 0.12 & 0.65 & 0.64 & -2.5 \\
\hline MELB & F14 & Ocean & 0.134 & 0.128 & 0.63 & 0.63 & -4.0 \\
\hline MELB & F15 & Ocean & 0.144 & 0.144 & 0.7 & 0.69 & 0.5 \\
\hline MELB & N15 & Ocean & 0.143 & 0.123 & 0.54 & 0.56 & -13.9 \\
\hline MELB & N16 & Ocean & 0.136 & 0.111 & 0.53 & 0.51 & -18.1 \\
\hline MELB & N17 & Ocean & 0.132 & 0.094 & 0.47 & 0.53 & -28.9 \\
\hline MELB & AMSR & Ocean & 0.153 & 0.145 & 0.69 & 0.83 & -5.3 \\
\hline MELB & TMI & Ocean & 0.131 & 0.116 & 0.65 & 0.83 & -11.3 \\
\hline$M E L B$ & $F 13$ & Land & 0.169 & 0.212 & 0.72 & 0.64 & 25.5 \\
\hline$M E L B$ & $F 14$ & Land & 0.11 & 0.127 & 0.69 & 0.67 & 16.0 \\
\hline$M E L B$ & $F 15$ & Land & 0.114 & 0.128 & 0.68 & 0.67 & 13.1 \\
\hline$M E L B$ & N15 & Land & 0.181 & 0.212 & 0.52 & 0.5 & 17.1 \\
\hline$M E L B$ & N16 & Land & 0.18 & 0.166 & 0.46 & 0.49 & -7.7 \\
\hline$M E L B$ & N17 & Land & 0.094 & 0.077 & 0.45 & 0.57 & -18.3 \\
\hline$M E L B$ & $A M S R$ & Land & 0.164 & 0.163 & 0.71 & 0.72 & -1.2 \\
\hline$M E L B$ & $T M I$ & Land & 0.14 & 0.157 & 0.79 & 0.73 & 12.3 \\
\hline MELB & F13 & Coast & 0.125 & 0.185 & 0.9 & 0.63 & 48.4 \\
\hline MELB & F14 & Coast & 0.114 & 0.195 & 1.04 & 0.65 & 71.1 \\
\hline MELB & F15 & Coast & 0.118 & 0.17 & 0.91 & 0.68 & 44.4 \\
\hline MELB & N15 & Coast & 0.148 & 0.148 & 0.48 & 0.48 & 0.5 \\
\hline MELB & N16 & Coast & 0.166 & 0.143 & 0.44 & 0.48 & -14.2 \\
\hline MELB & N17 & Coast & 0.094 & 0.054 & 0.36 & 0.53 & -42.9 \\
\hline MELB & AMSR & Coast & 0.172 & 0.158 & 0.65 & 0.67 & -8.2 \\
\hline MELB & TMI & Coast & 0.135 & 0.118 & 0.66 & 0.74 & -12.9 \\
\hline$M E L B$ & $F 13$ & All & 0.137 & 0.175 & 0.77 & 0.63 & 28.1 \\
\hline$M E L B$ & $F 14$ & All & 0.118 & 0.158 & 0.82 & 0.63 & 33.5 \\
\hline$M E L B$ & $F 15$ & All & 0.124 & 0.151 & 0.78 & 0.67 & 22.5 \\
\hline$M E L B$ & N15 & All & 0.156 & 0.16 & 0.51 & 0.5 & 2.5 \\
\hline$M E L B$ & $N 16$ & All & 0.162 & 0.141 & 0.46 & 0.49 & -13.0 \\
\hline$M E L B$ & $N 17$ & All & 0.104 & 0.071 & 0.42 & 0.54 & -31.8 \\
\hline$M E L B$ & $A M S R$ & All & 0.165 & 0.156 & 0.68 & 0.72 & -5.5 \\
\hline$M E L B$ & $T M I$ & All & 0.136 & 0.13 & 0.7 & 0.74 & -4.2 \\
\hline
\end{tabular}


Table 4: Contingency table construction used for calculating the Heidke Skill Score and other metrics. In our study, satellite estimates are "Observed", while validation estimates are "Predicted."

\begin{tabular}{|l|c|c|}
\hline & Observed Yes & Observed No \\
\hline Predicted Yes & A (Hits) & C (False Alarms) \\
\hline Predicted No & B (Misses) & D (Correct Rejections \\
\hline
\end{tabular}




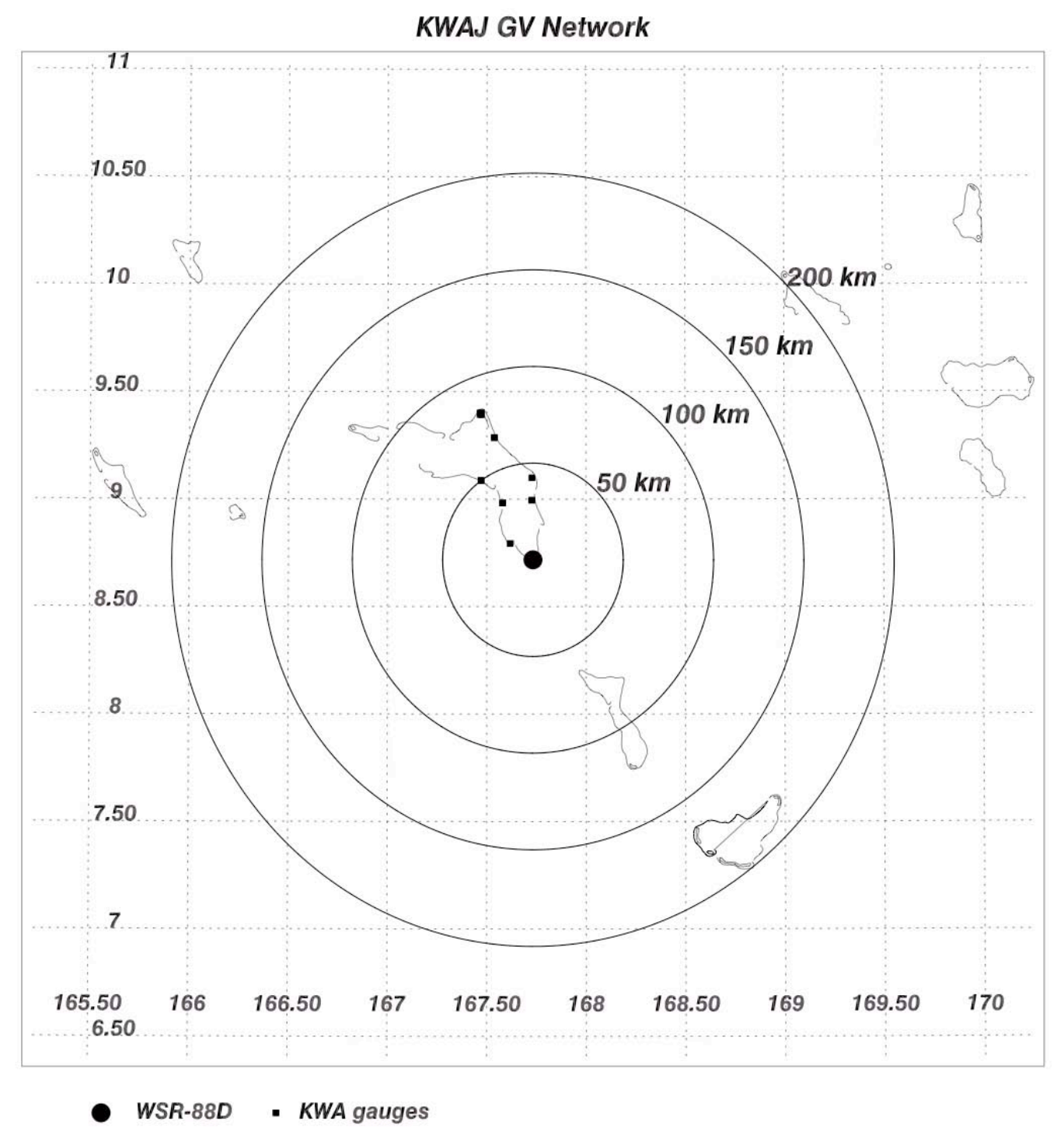

Fig. 1a: Illustration of the gauge and radar networks for the GV network at KWAJ. Range rings at 50,100, 150 and $200 \mathrm{~km}$ are also shown. Note that for this study, all usable GV data was restricted to the first $100 \mathrm{~km}$ from each respective radar site. KWAJ has only seven gauge sites; however, each site contains two or more gauges to improve reliability and uncertainty of the measured rain rates. 


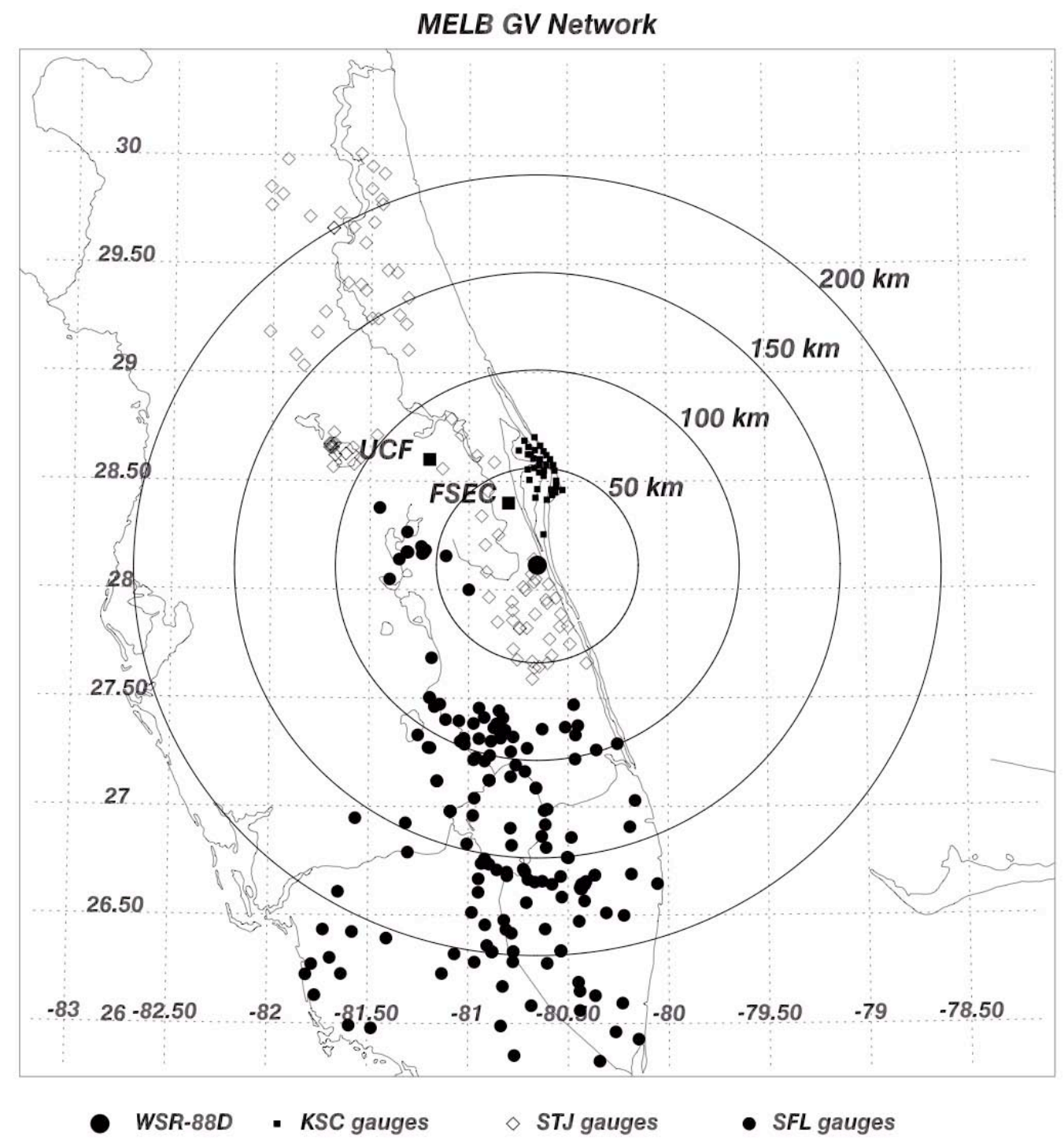

Fig. 1b: Same as Fig. 1a, except for MELB. There are three gange networks in Florida: St. John's River Water Management District (STJ), and the South Florida Water Management District (SFL). Both of these networks are operated by the state of Florida. A NASA-owned network is located on Cape Canaveral at NASA Kennedy Space Center. 


\section{GPROF Terrain Mask for KWAJ}

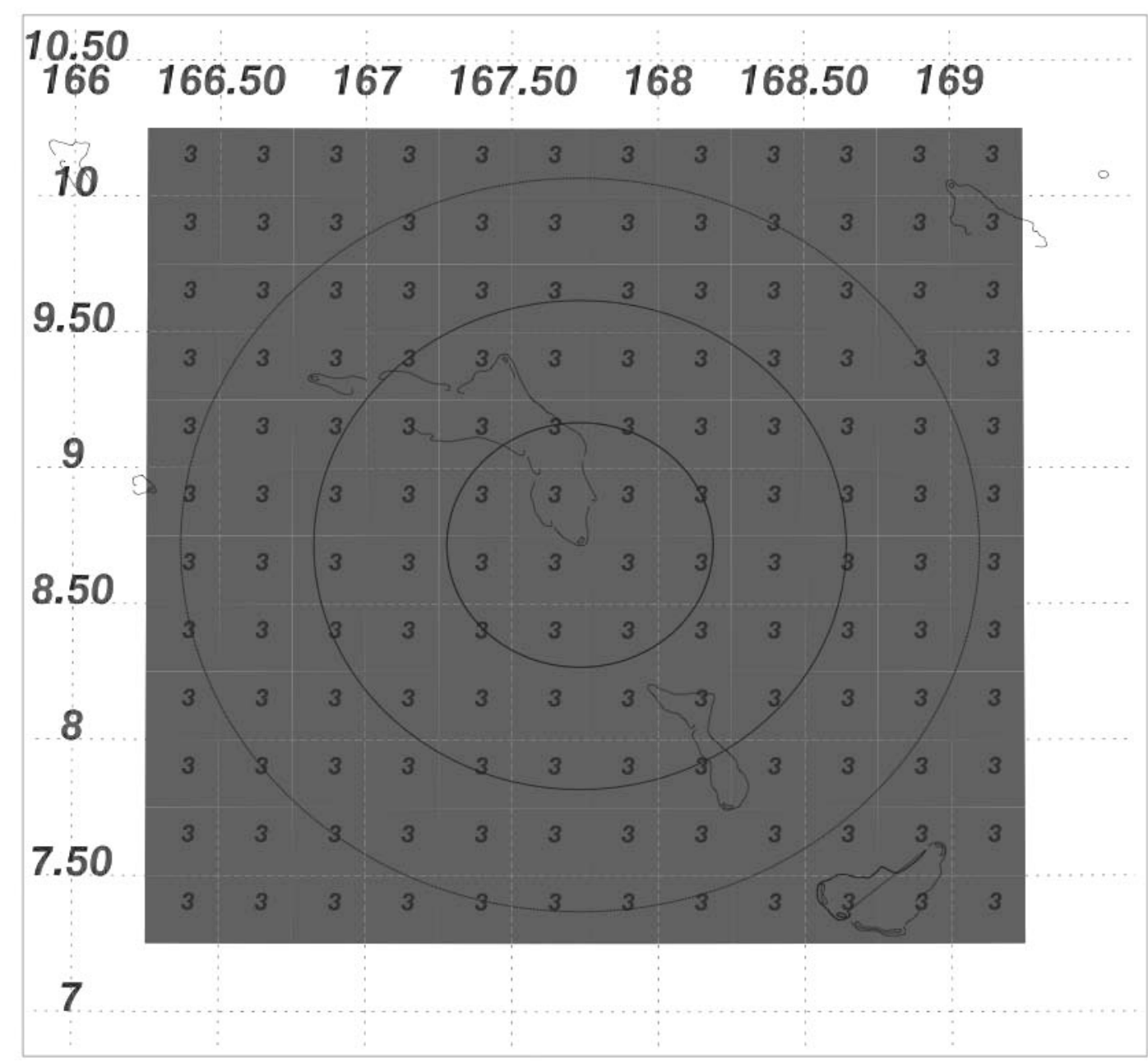

Fig. 2a: Terrain masks for the KWAJ GV site. Each $0.25^{\circ}$ grid box is designated as ocean (3), land (0), coastal-water (4), or coastal land (5). Both coastal-land and coastal-water are treated together as "coast" in this study. The respective GV radar is located at the center of each image and range rings at $50 \mathrm{~km}, 100 \mathrm{~km}$ and $150 \mathrm{~km}$ are also shown. 


\section{GPROF Terrain Mask for MELB}

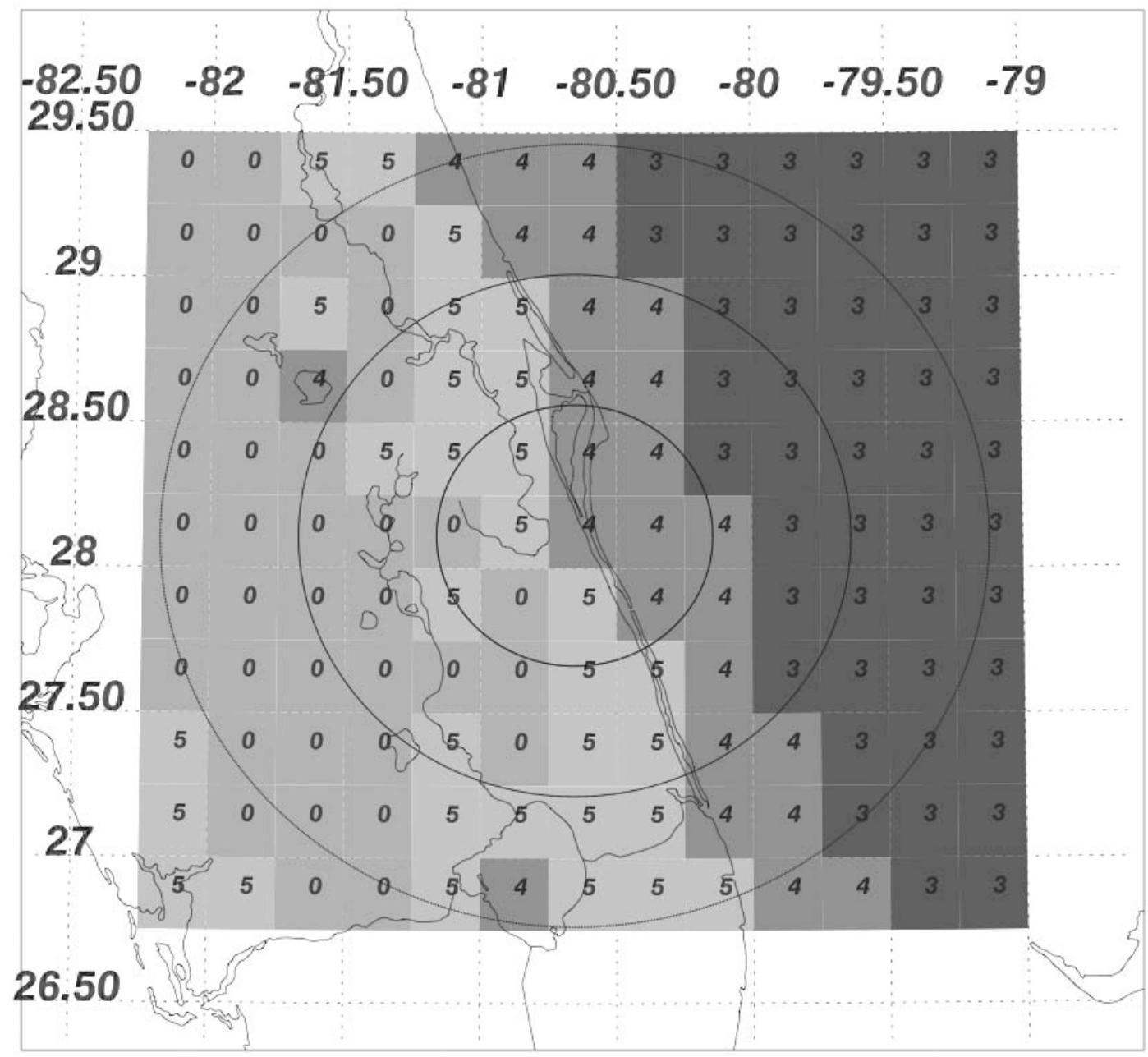

Fig. 2b: Same as Fig. 2a, except for MELB 


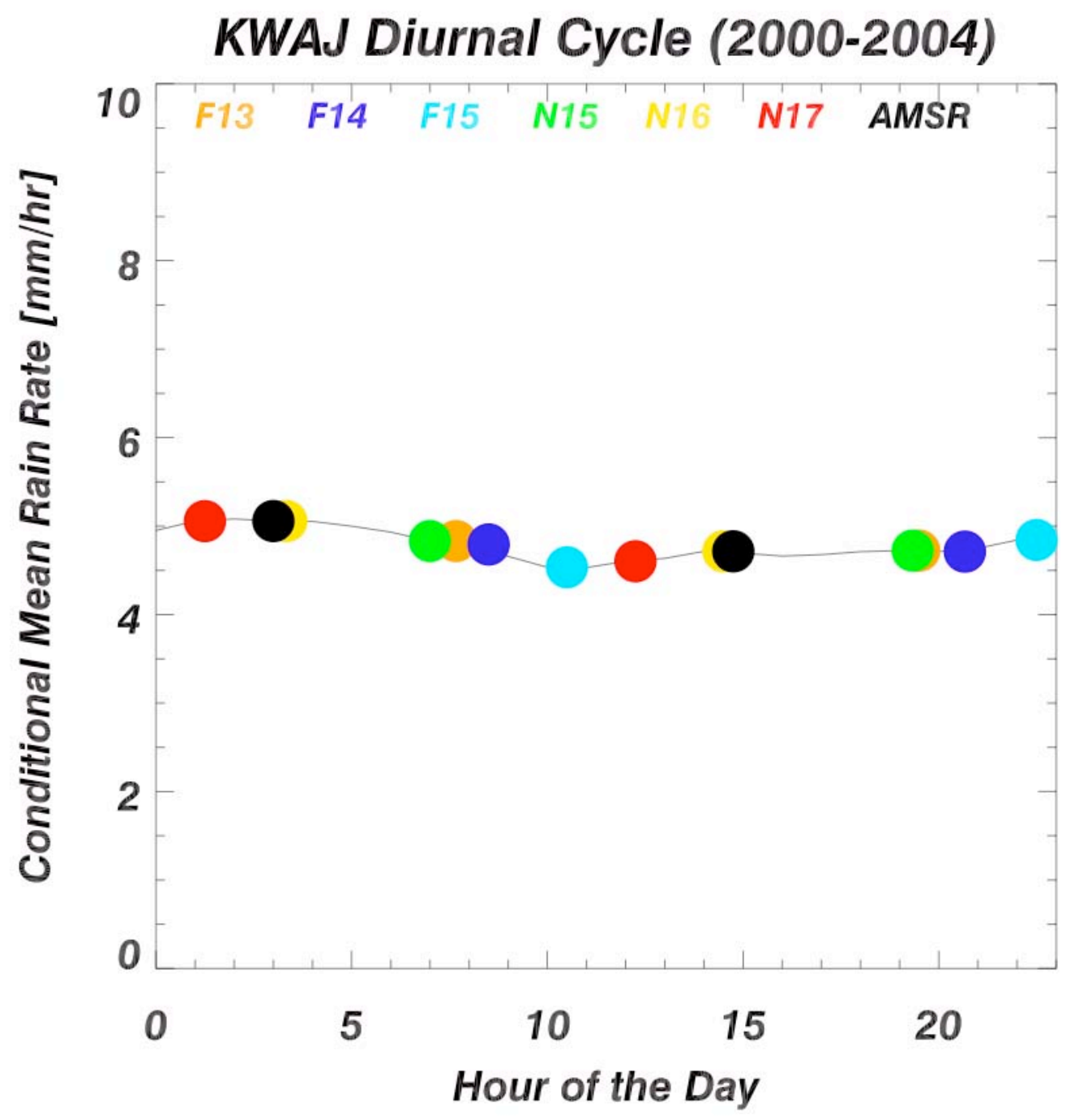

Fig. 3a: Diurnal cycle of hourly conditional mean rain rate, derived from seven years (2000-2006) of GV data at HSTN. Superimposed are colored symbols showing the local overpass times of each of the polar-orbiting satellites assessed in this study. 


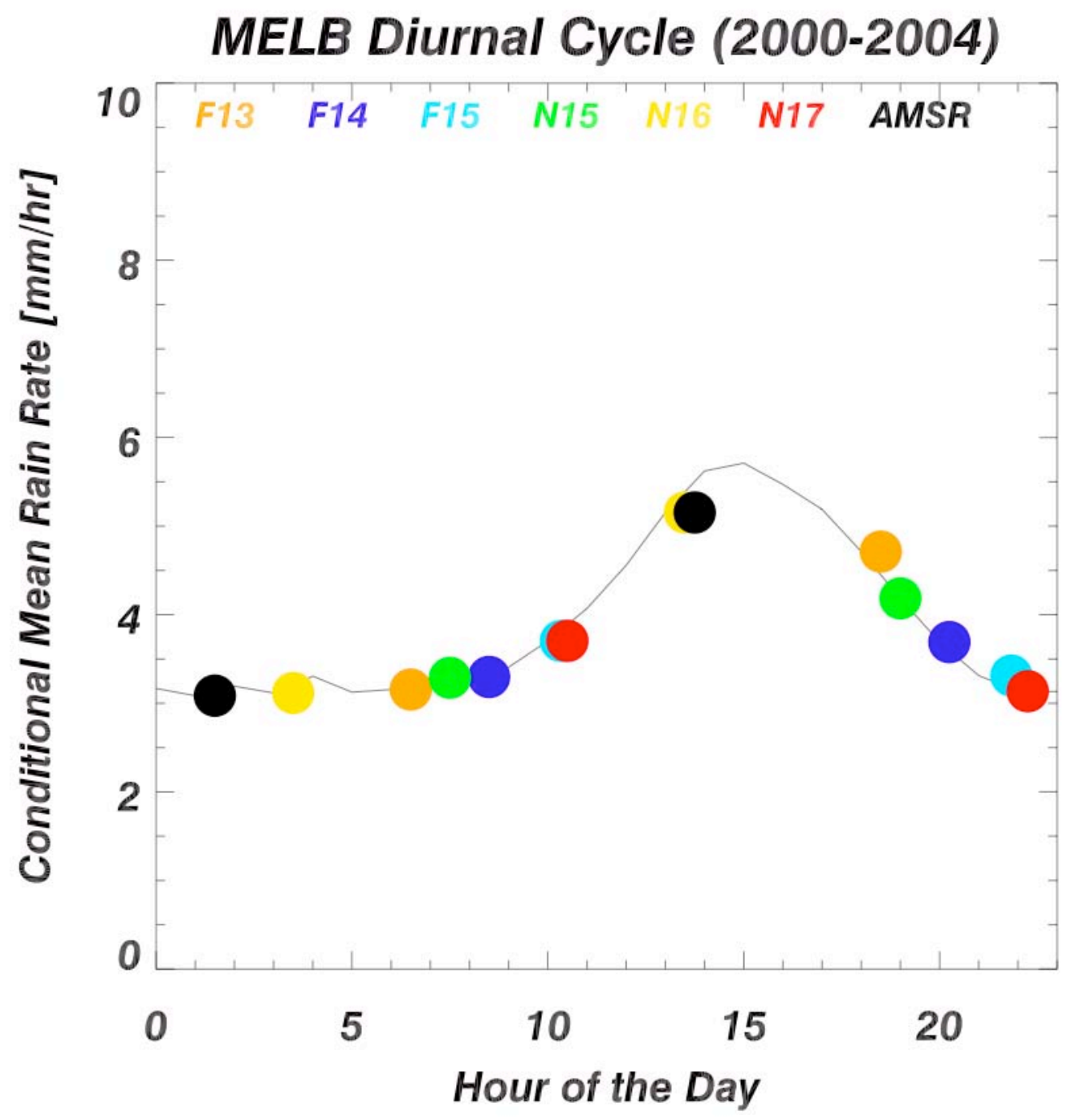

Fig. 3b: Same as Fig. 2a, except for MELB. 

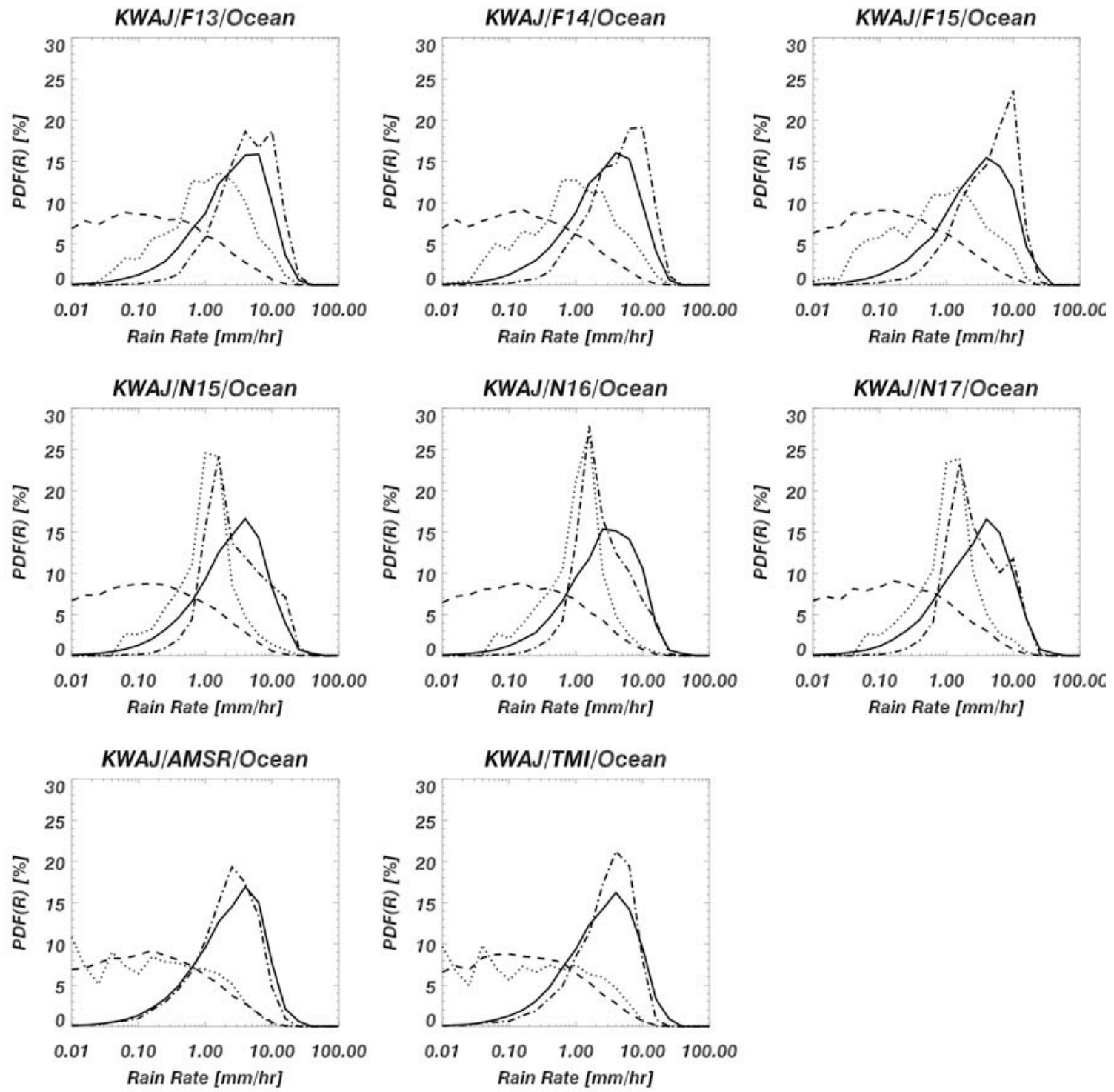

Fig. 4: Probability density functions (PDF) of rain rates for TRMM GV and the various satellite retrievals at KWAJ. The dashed and dotted lines represent the PDF by occurrence $P D F_{c}=P D F(R)$ for $G V$ and satellite, respectively, while the solid and dashdotted lines represent the PDF by volume $P D F_{v}=\left[R^{*} P D F(R)\right]$ for $G V$ and Satellite, respectively 

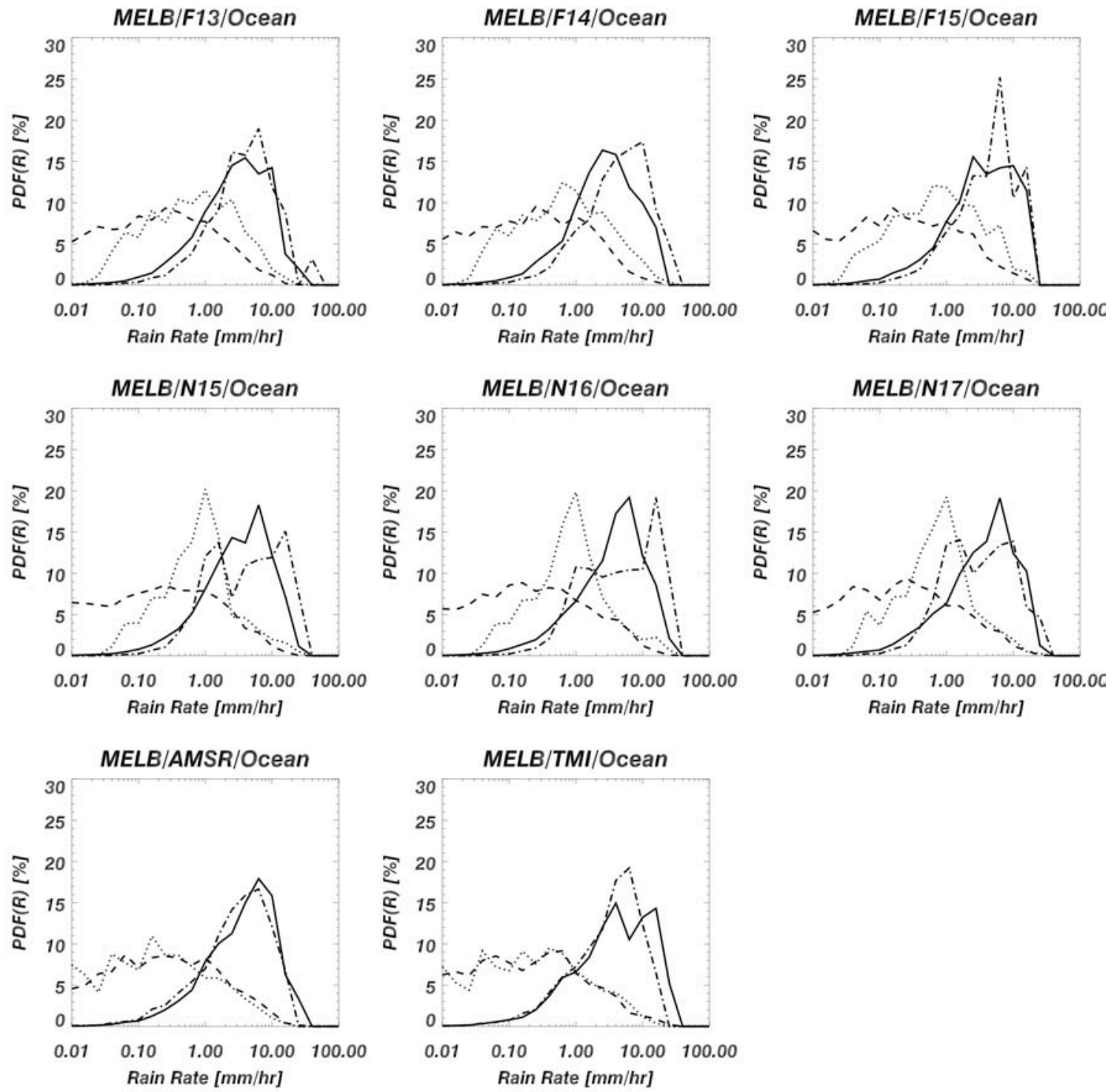

Fig.5a: Probability density functions (PDF) of rain rates for TRMM GV and the various satellite retrievals at MELB over ocean areas only. The dashed and dotted lines represent the $P D F$ by occurrence $P D F_{c}=(P D F(R)]$ for $G V$ and satellite respectively, while the solid and dash-dotted line represent the $P D F$ by volume $P D F_{v}=[R * P D F(R)]$. 

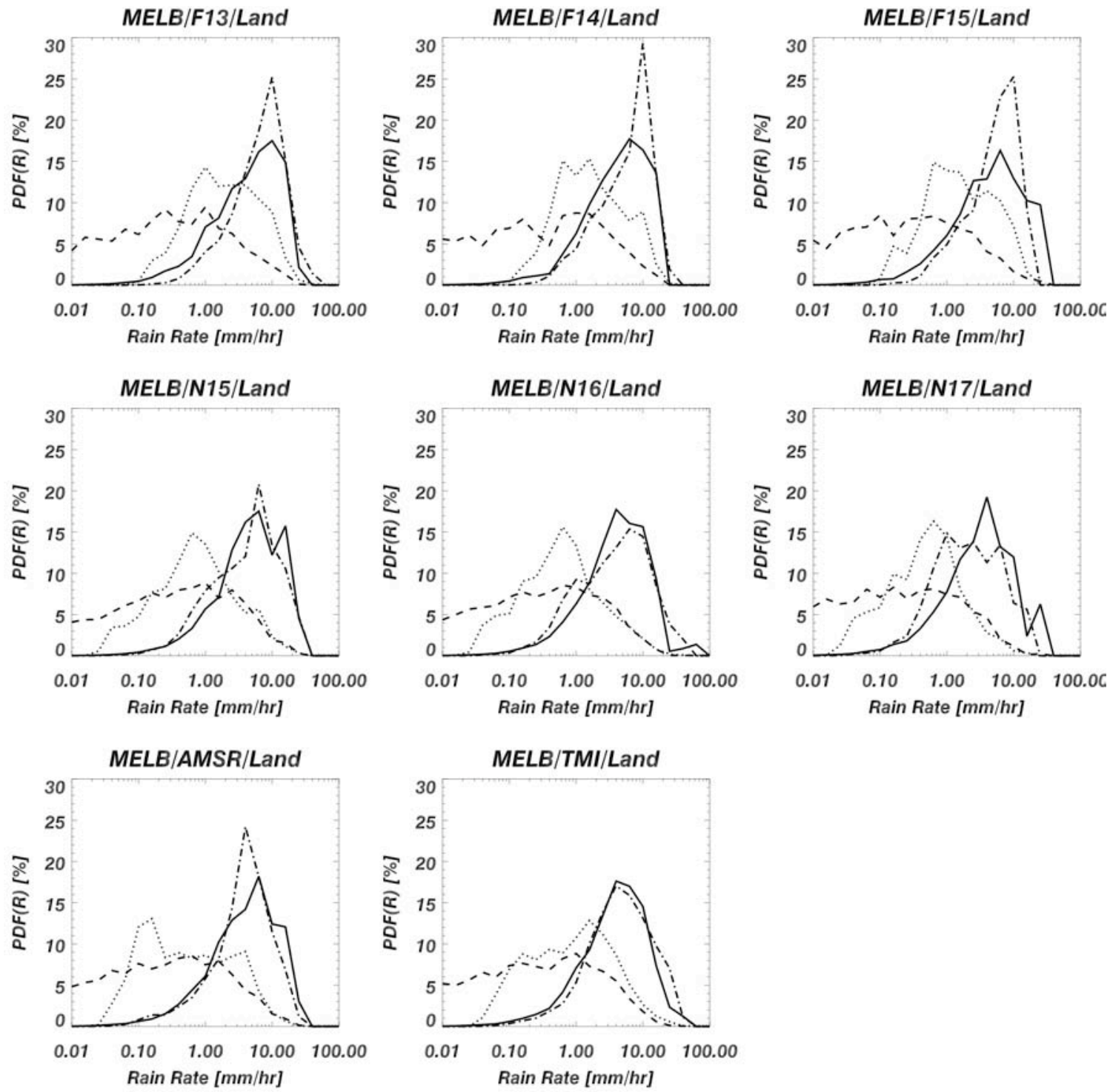

Fig 5b: Same as Fig. 5a, except over land areas only at MELB. 

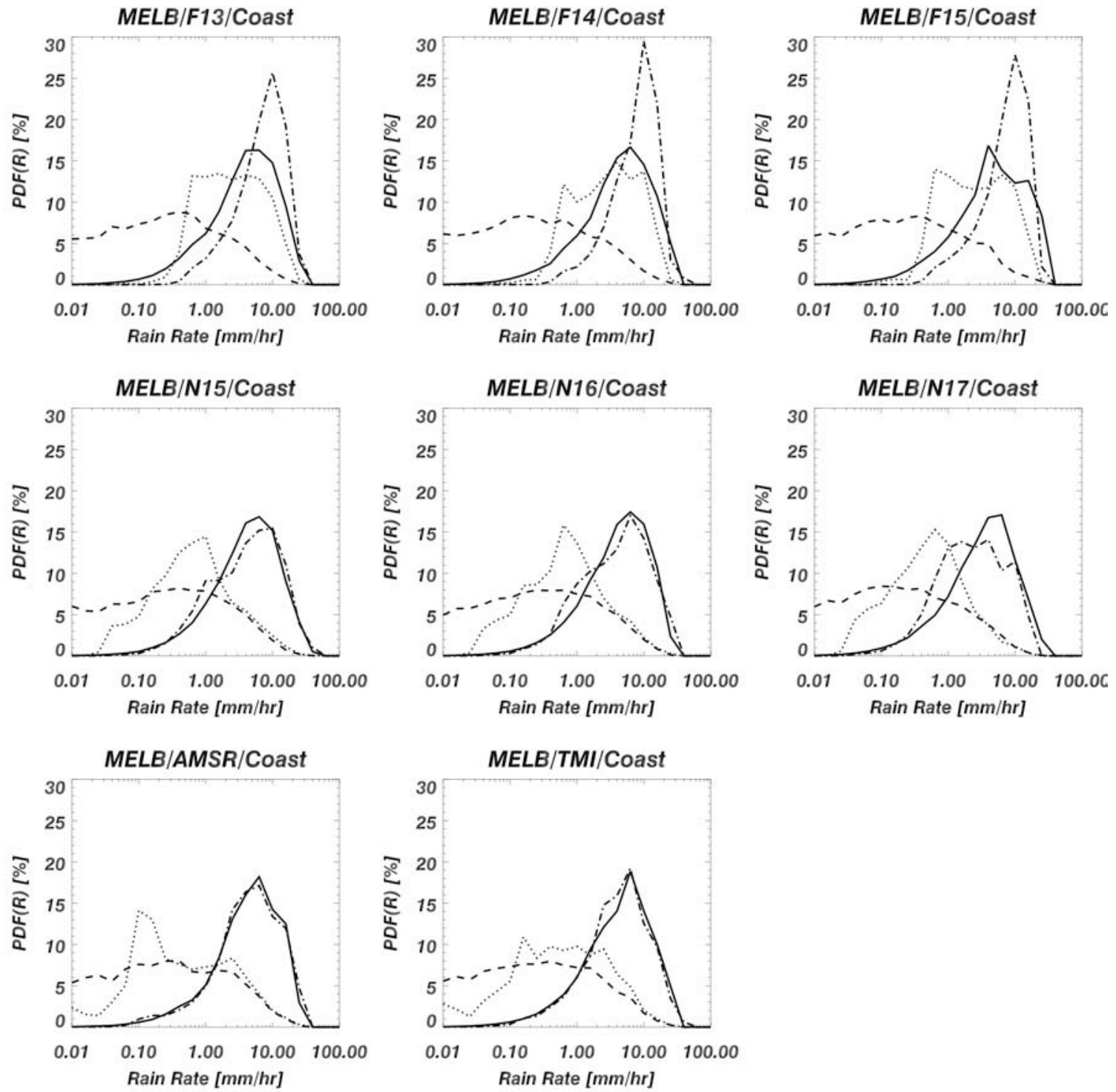

Fig. 5c: Same as Fig. 5a, except for coastal areas only at MELB. 

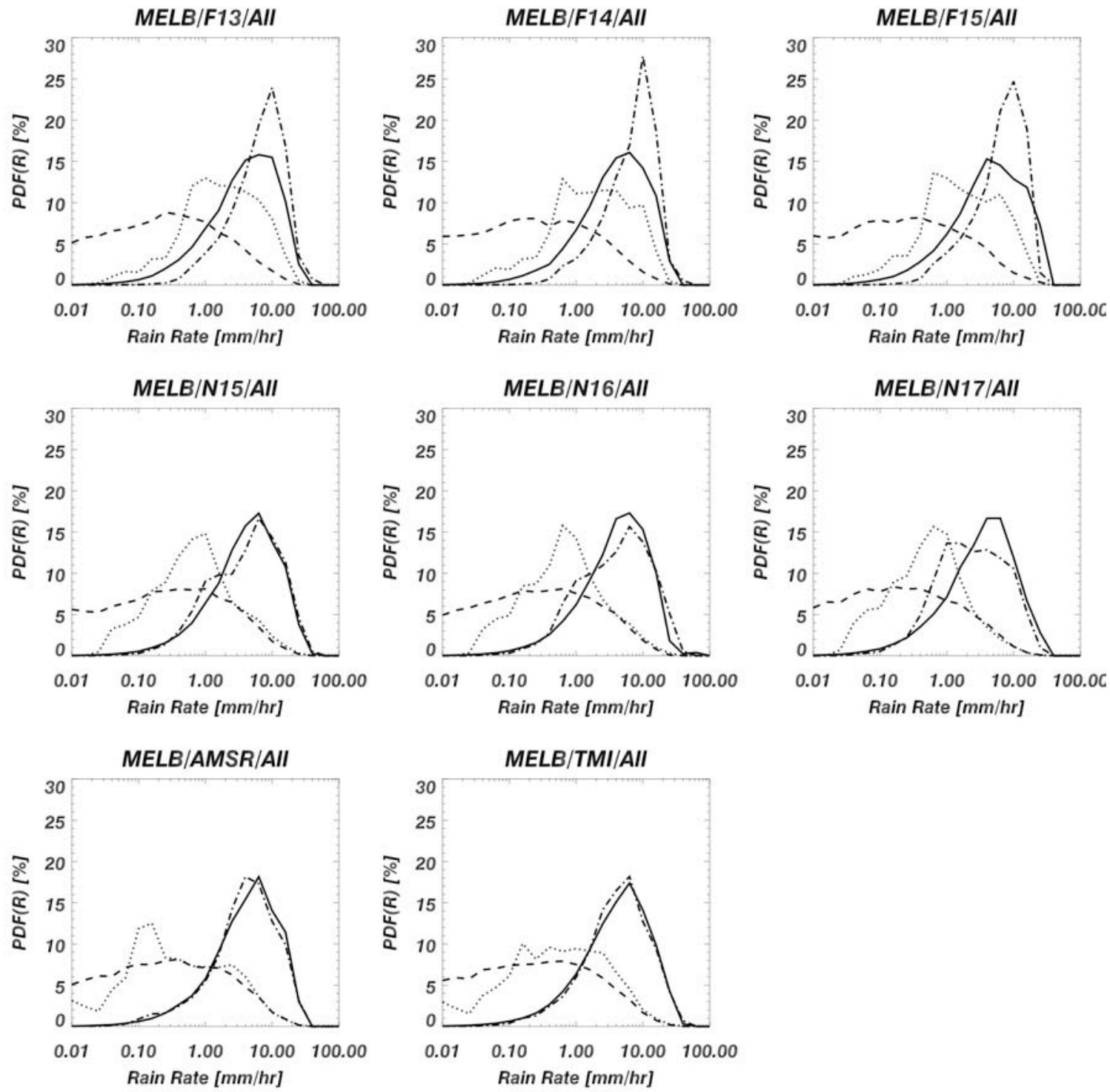

Fig. 5d: Same as Fig. 5a, except for the entire GV domain at MELB. 

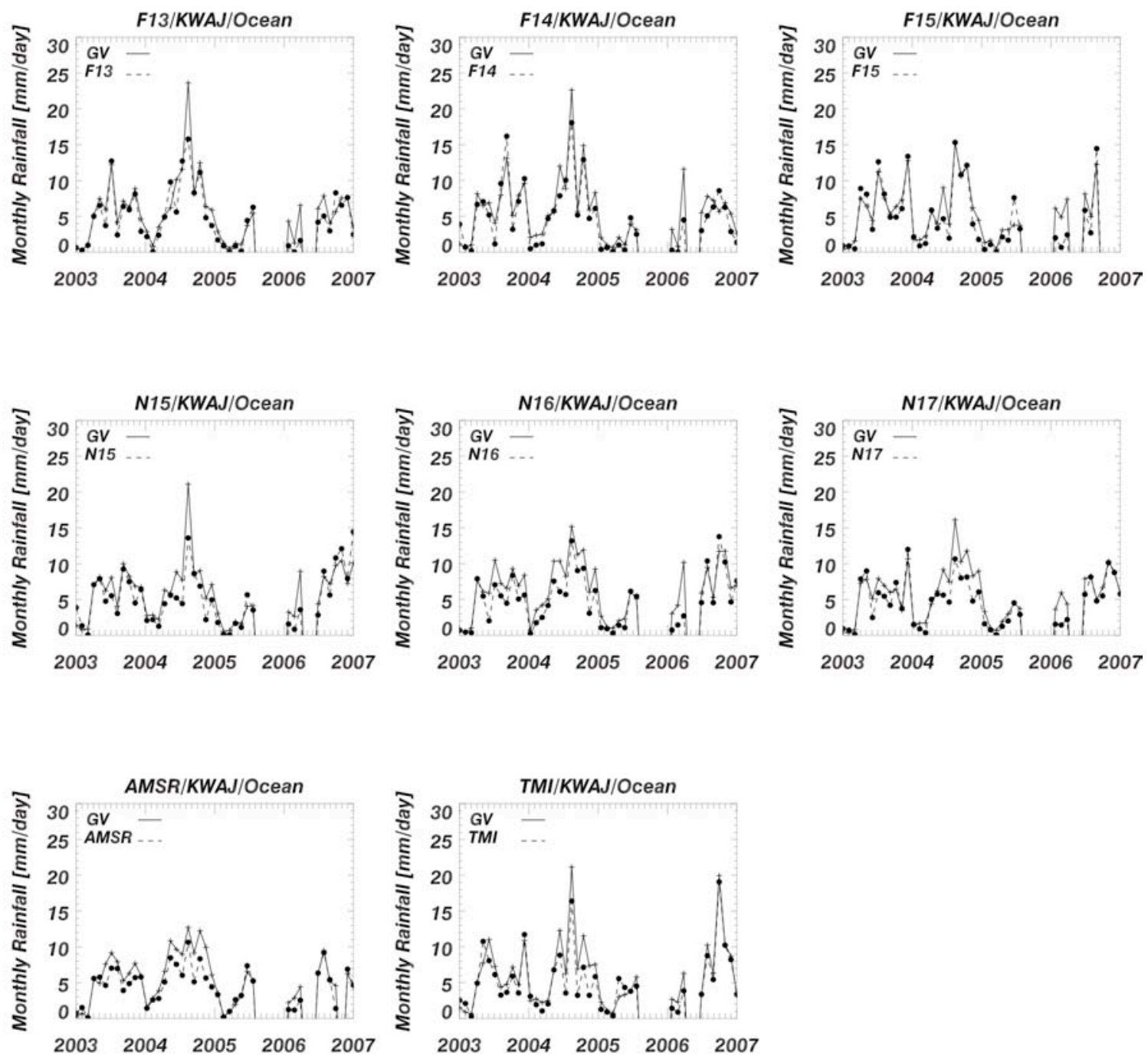

Fig. 6: Monthly rain computed estimates for KWAJ for each of the seven space-borne microwave estimates. Rain estimates only integrated matched $G V$-satellite rain rates during satellite overpasses. 

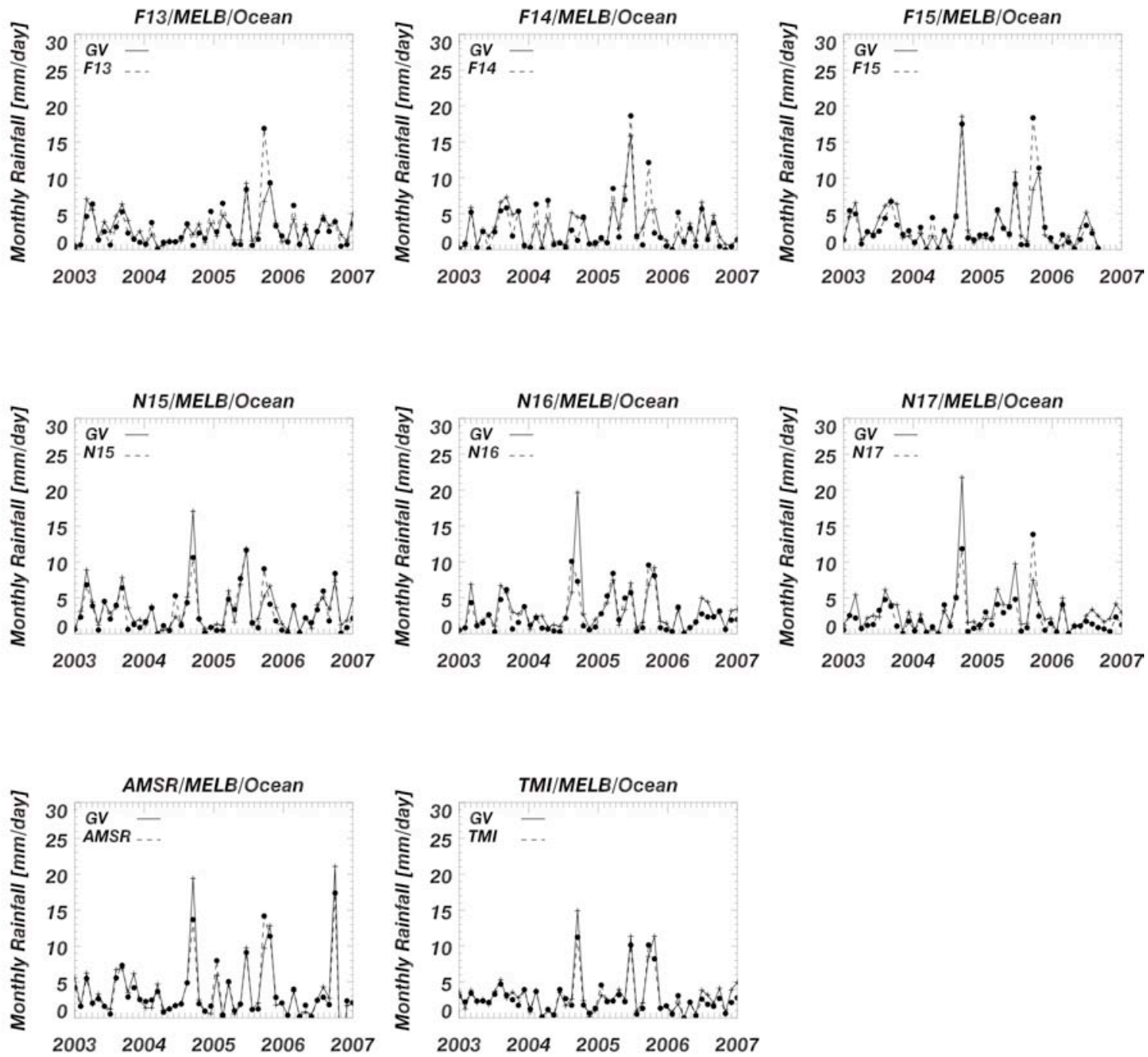

Fig. 7a: Same as Fig. 6, except for over ocean areas at MELB. 

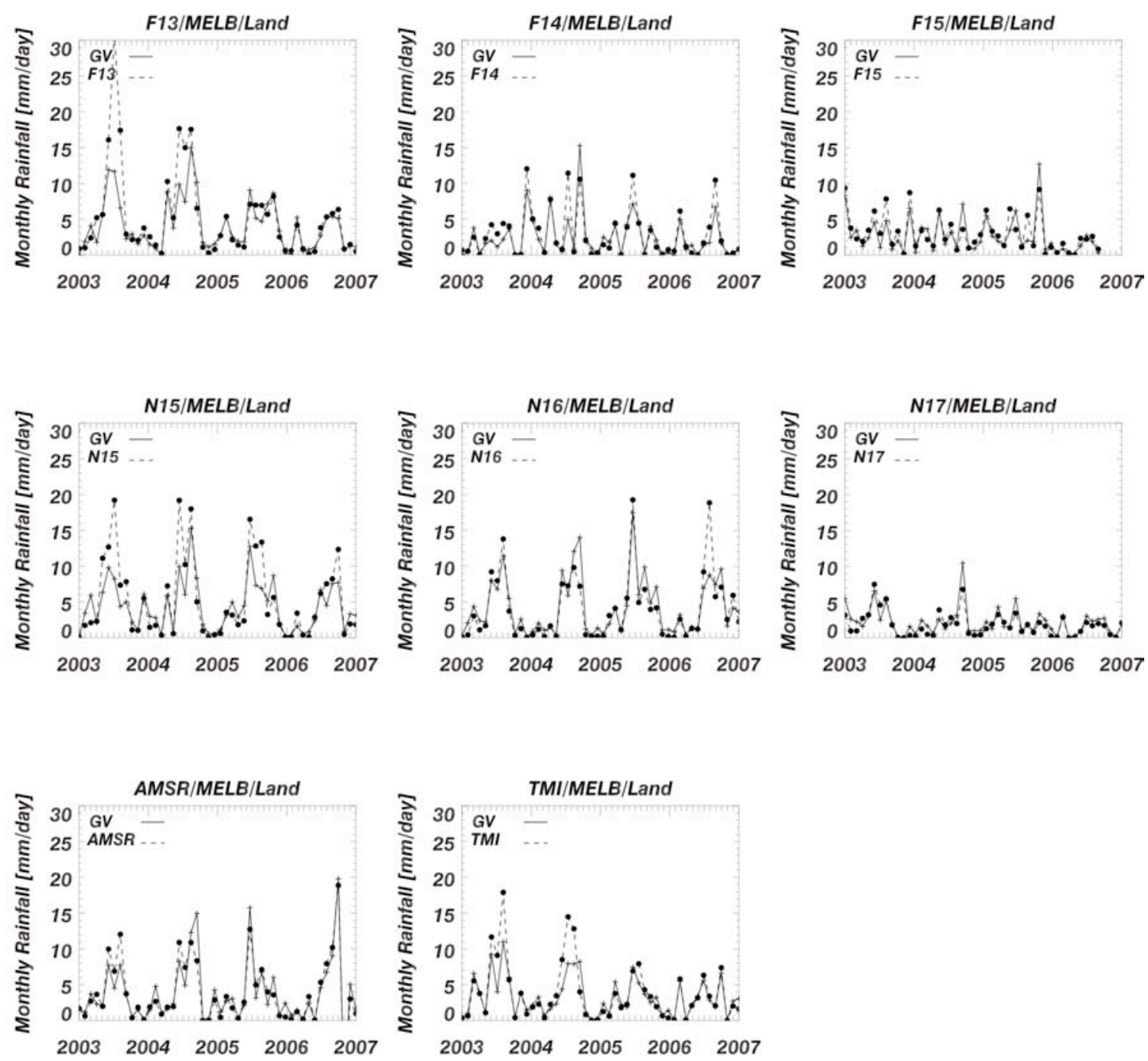

Fig. 7b: Same as Fig. 6, except for over land areas only at MELB. 

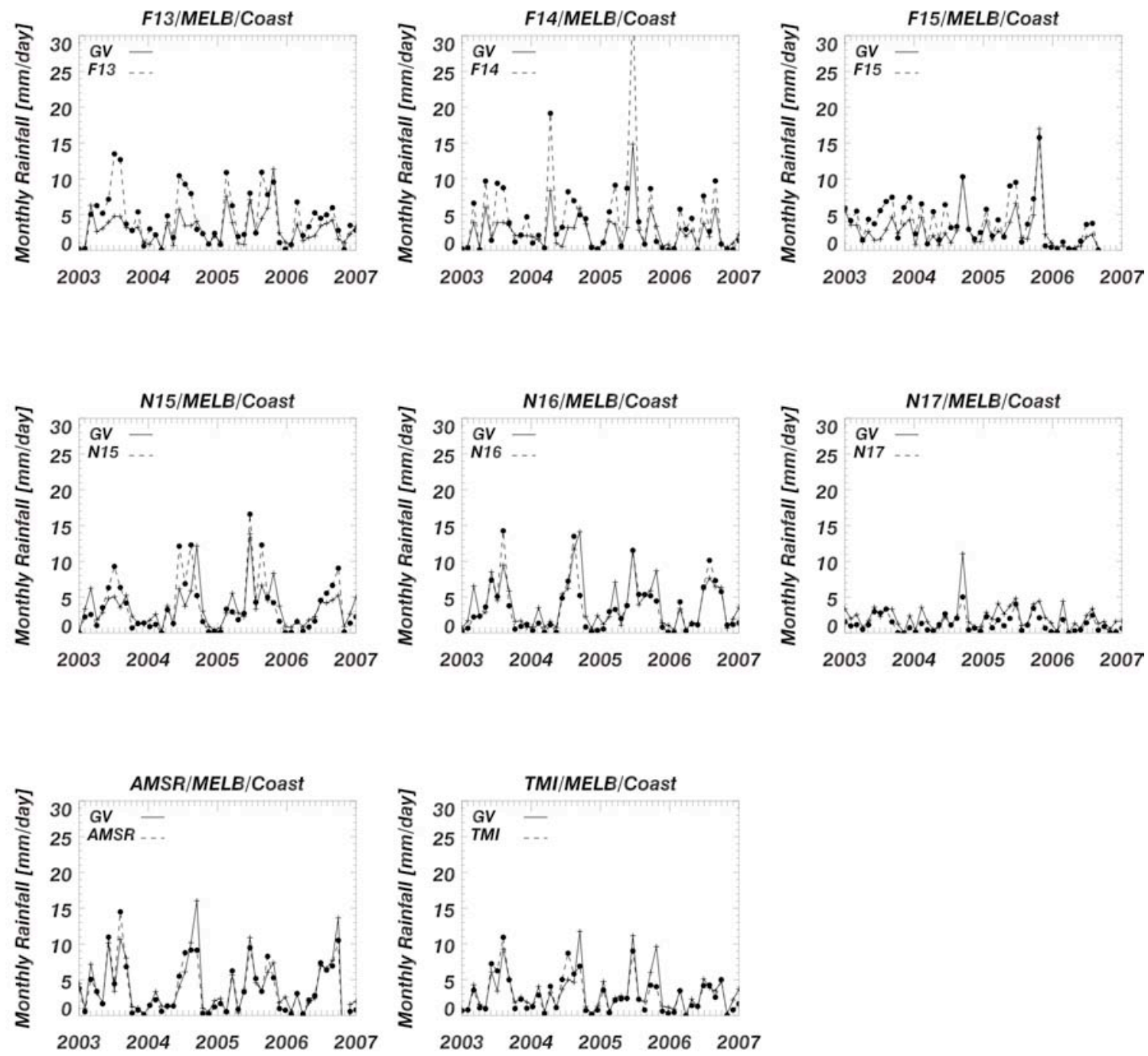

Fig. 7c: Same as Fig. 6, except for over coastal areas only at MELB. 

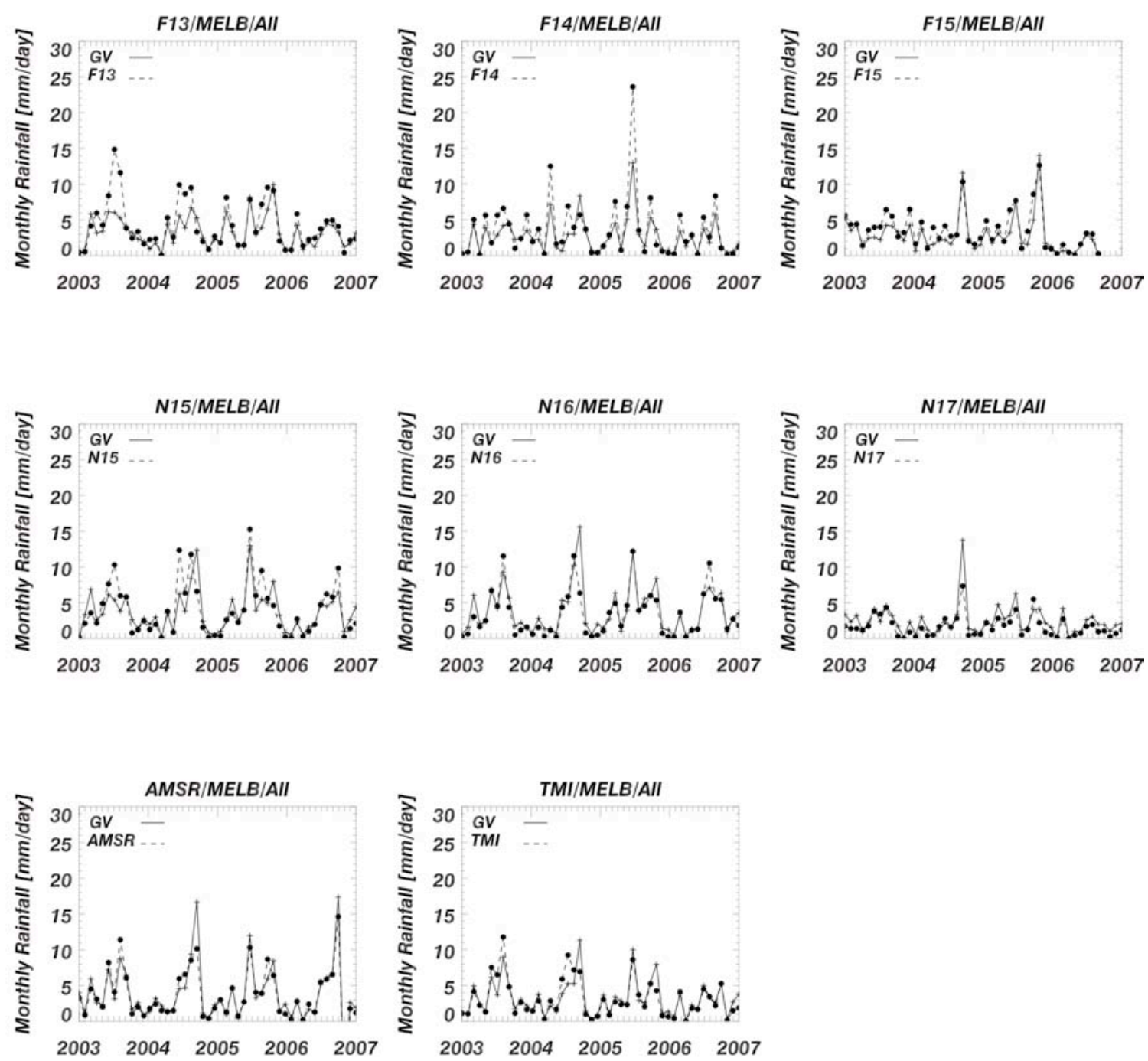

Fig. 7d: Same as Fig. 6, except for over the entire GV domain at MELB. 

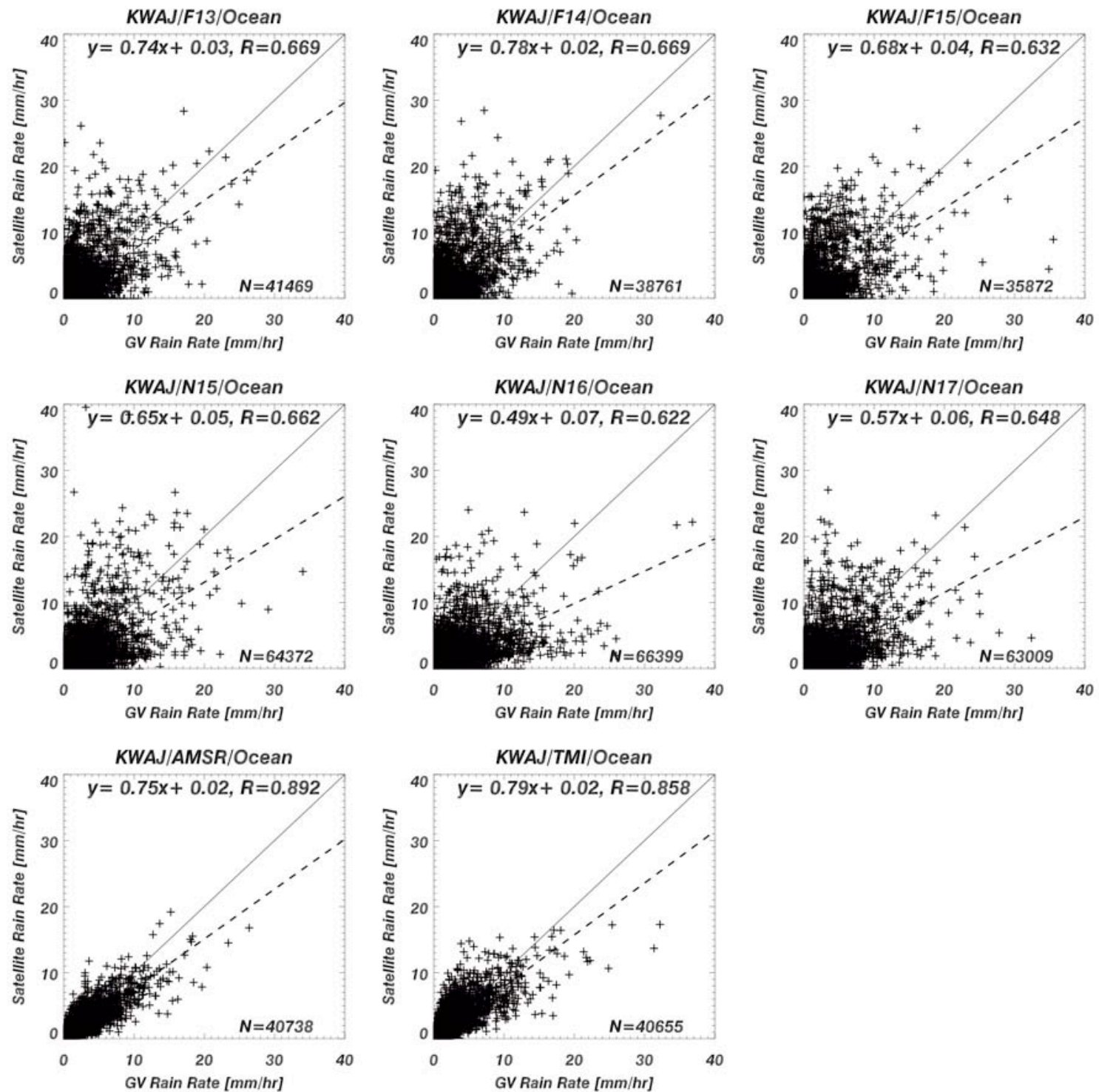

Fig 8: Scatter plots of instantaneous satellite and GV rain rates for KWAJ/Ocean for the period 2003-2006. 

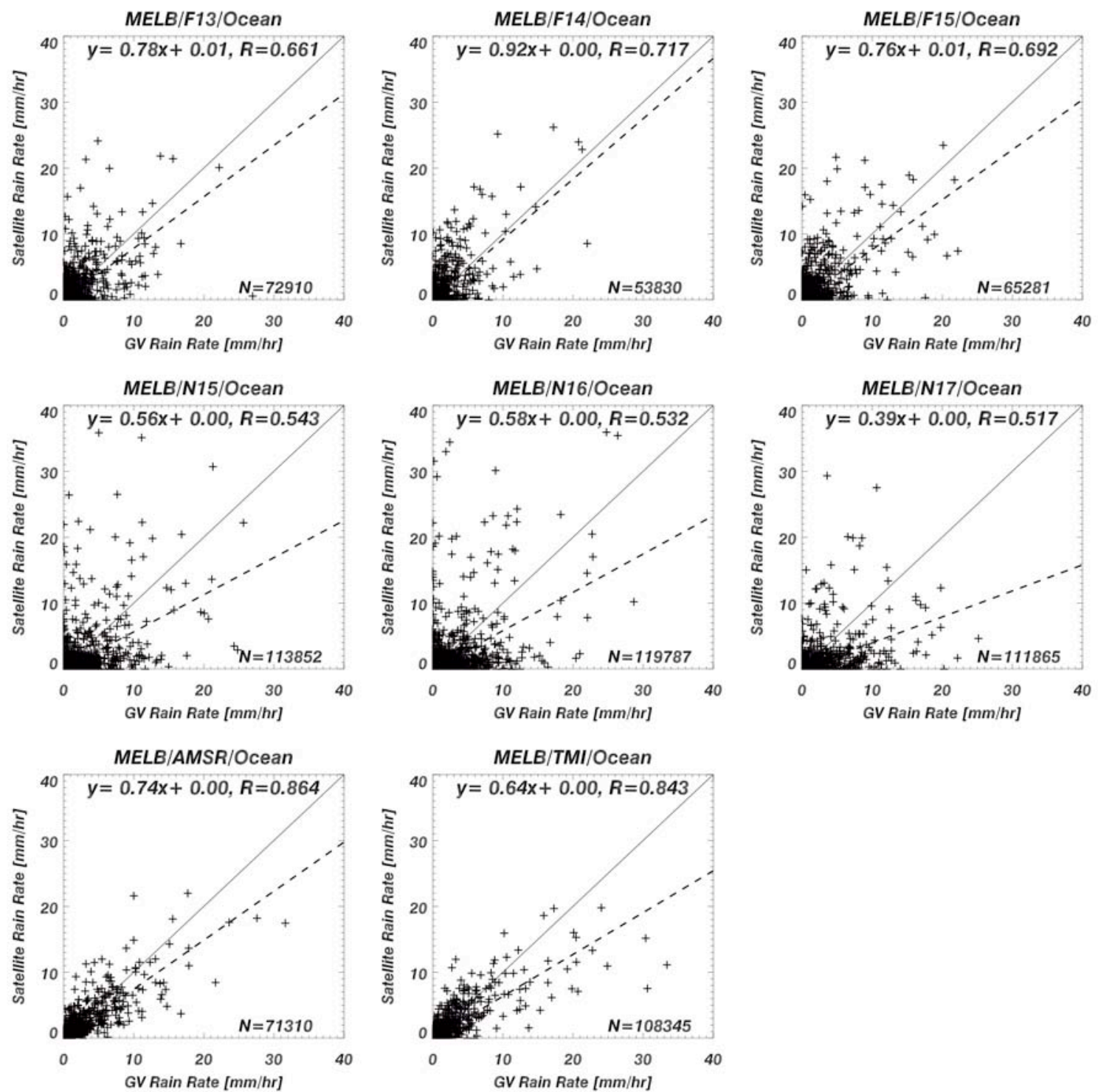

Fig 9a: Scatter plots of instantaneous satellite and GV rain rates for MELB over ocean areas only, for the period 2003-2006. 

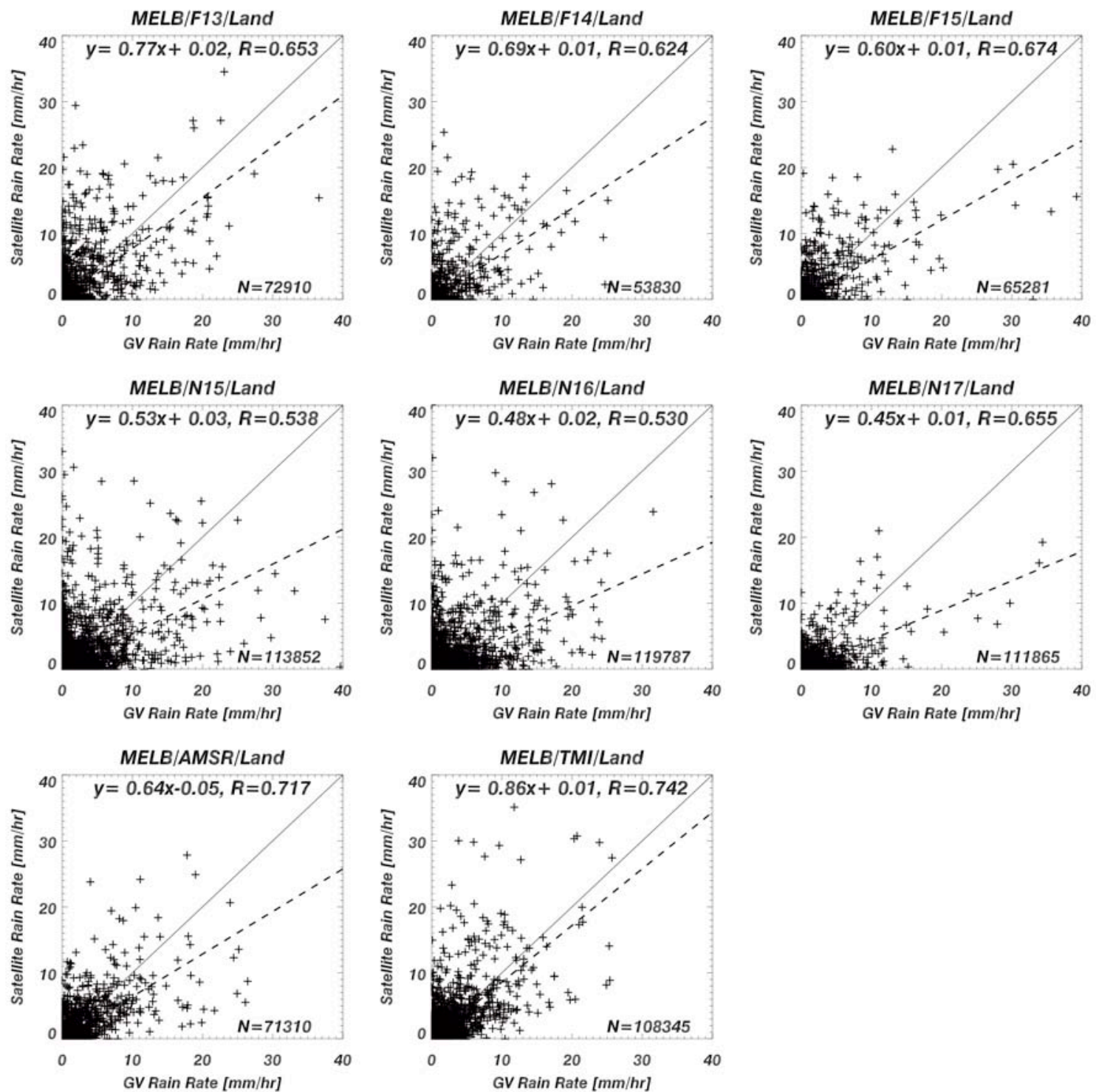

Fig 9b: Same as Fig. 9a but over land areas only. 

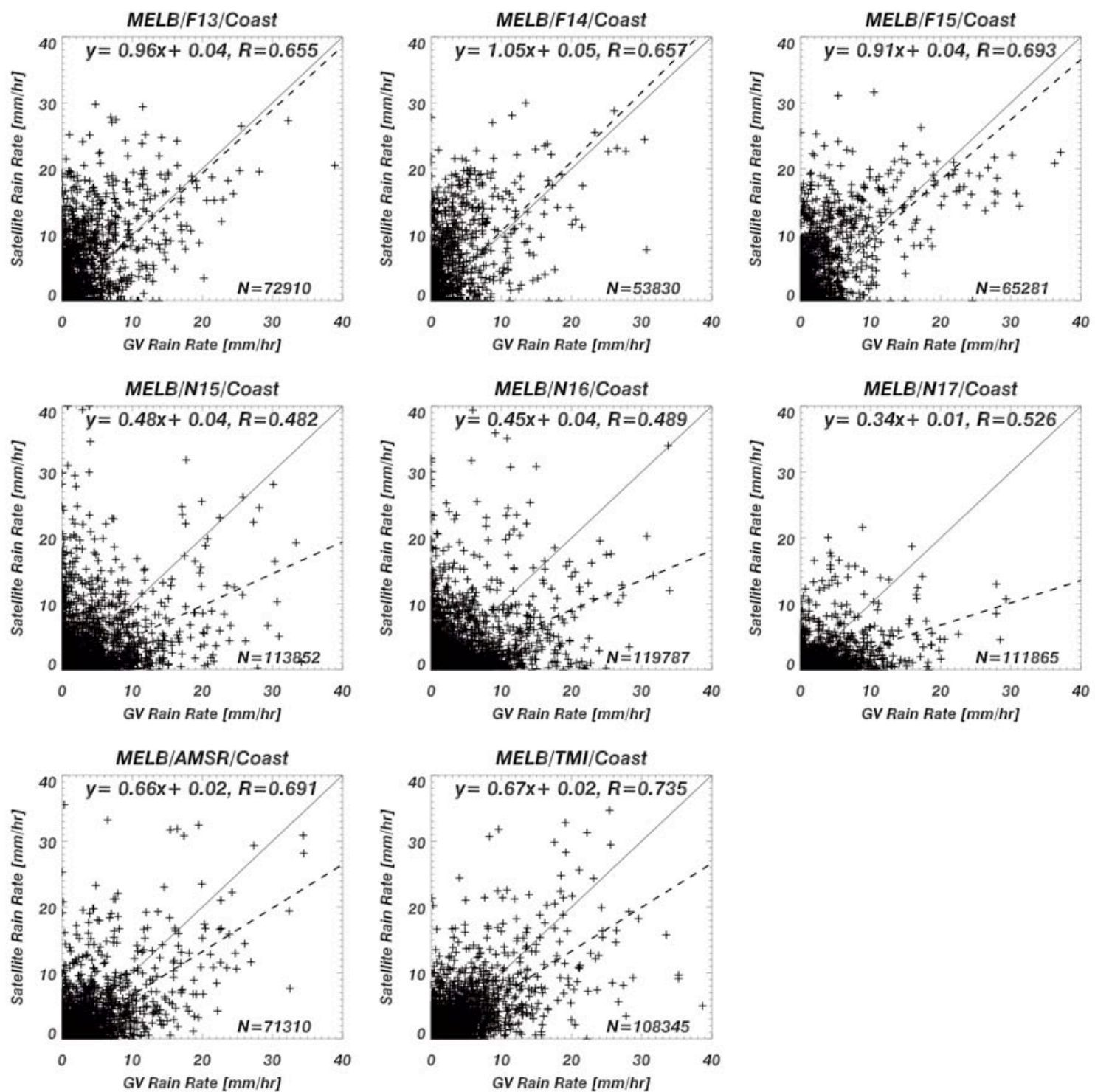

Fig 9c: Same as Fig. 9a but over coastal areas only. 

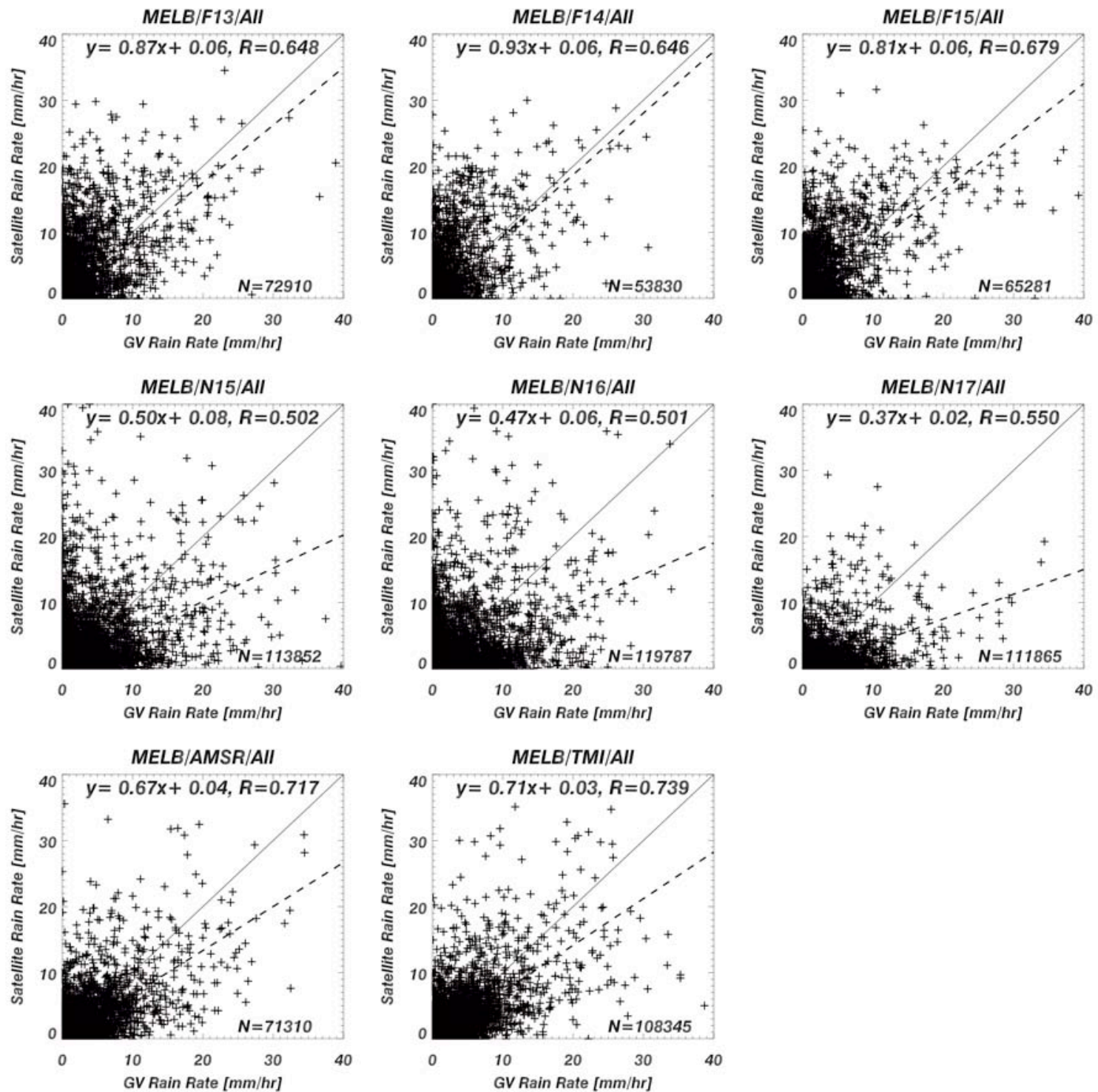

Fig. 9d: Same as Fig. 9a, but over the entire GV domain at MELB. 
KWAJ (Ocean)

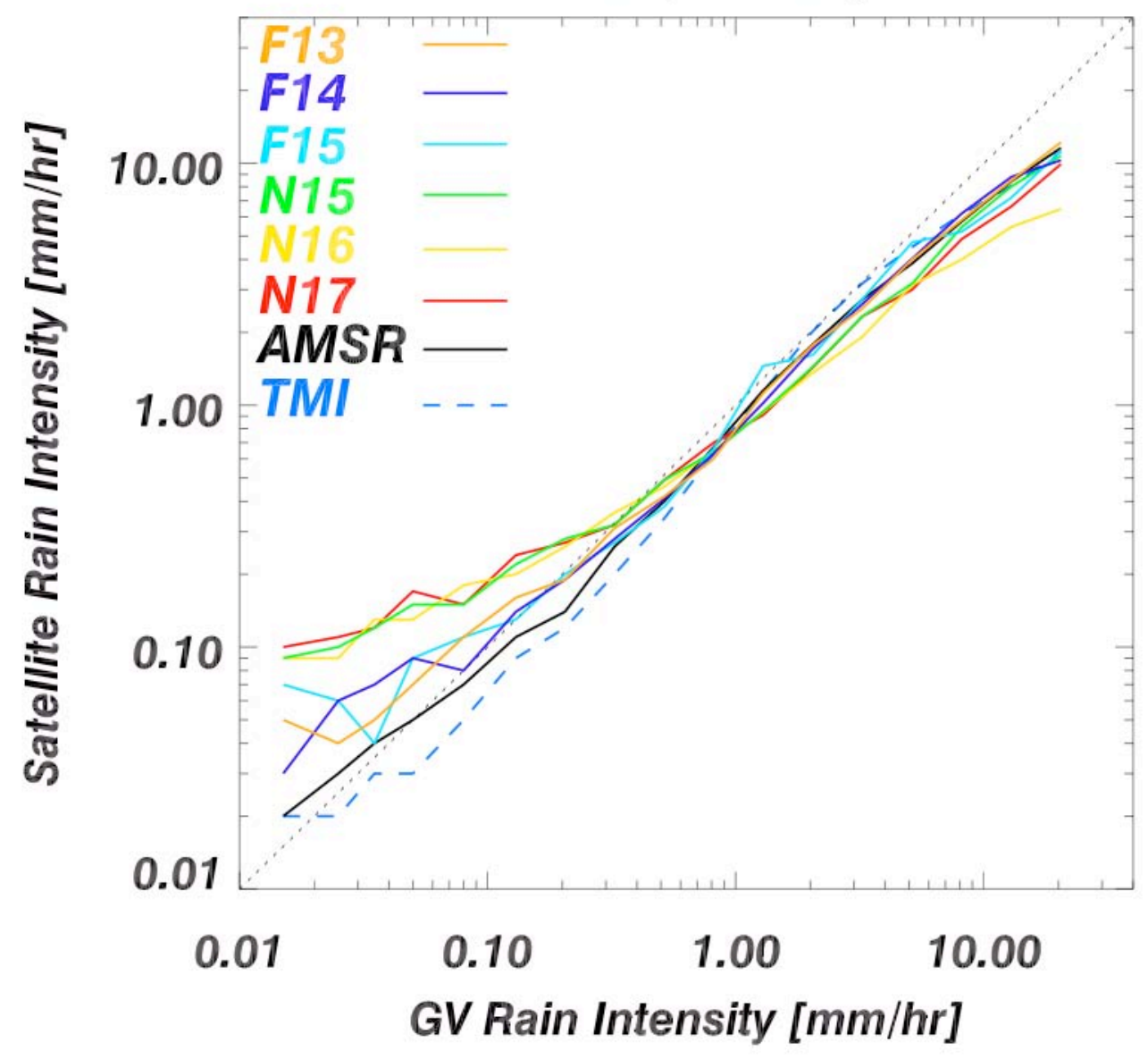

Fig. 10: Rain rate profiles for AMSR, F13, F14, F15, N15, N16 and N17 generated for $K W A J$ using $G V$ as an empirical reference. Satellite rain rates were binned and sorted along the $G V$ rain rate continuum. 

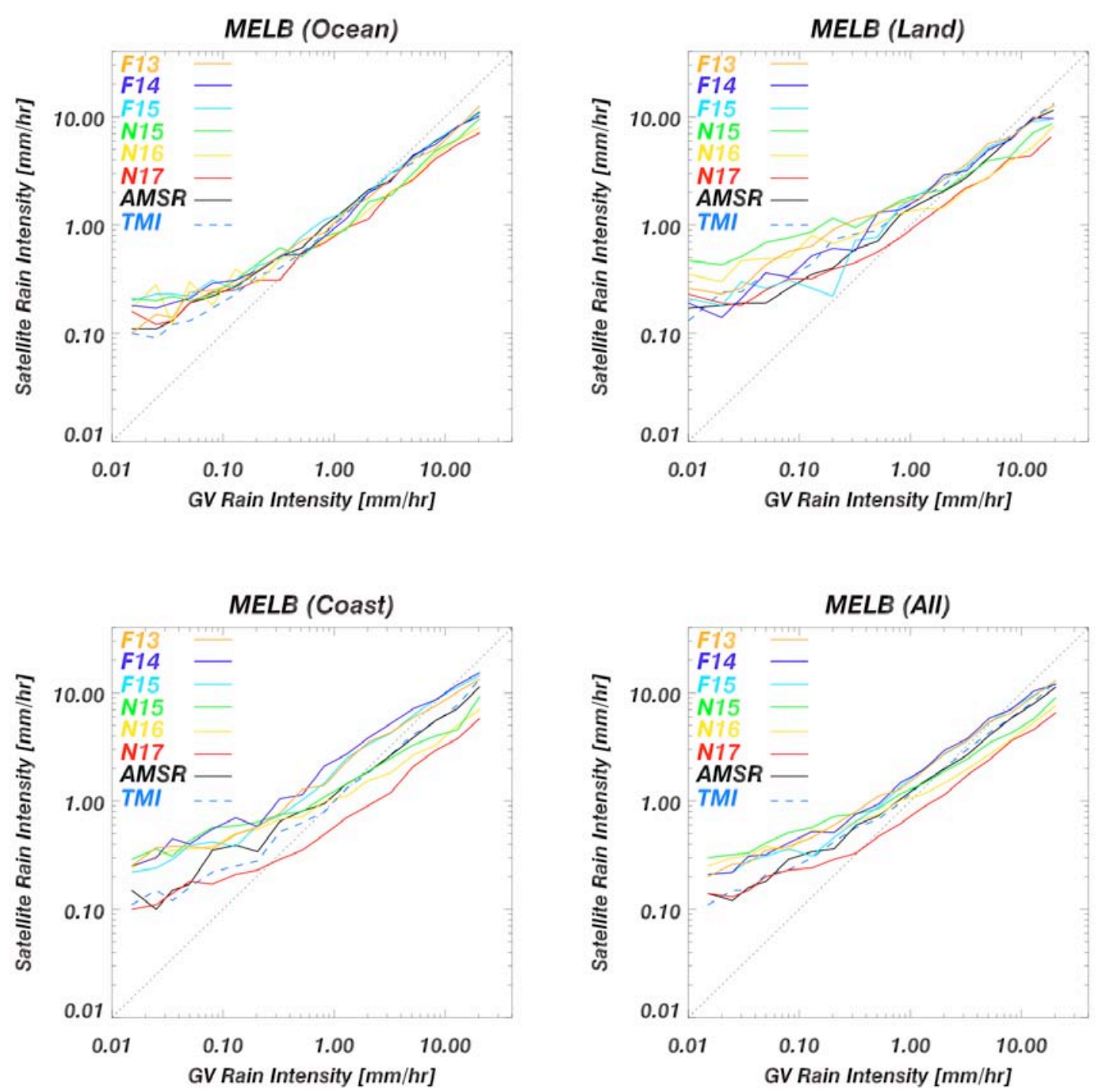

Fig. 11: Rain rate profiles for AMSR, F13, F14, F15, N15, N16 and N17 generated from matched $G V$-satellite data set for MELB using $G V$ as an empirical reference. Satellite rain rates were binned and sorted along the GV rain rate continuum. The matched data was further stratified according to Ocean (top left), Land (top right), Coast (bottom left) and All (bottom right). 

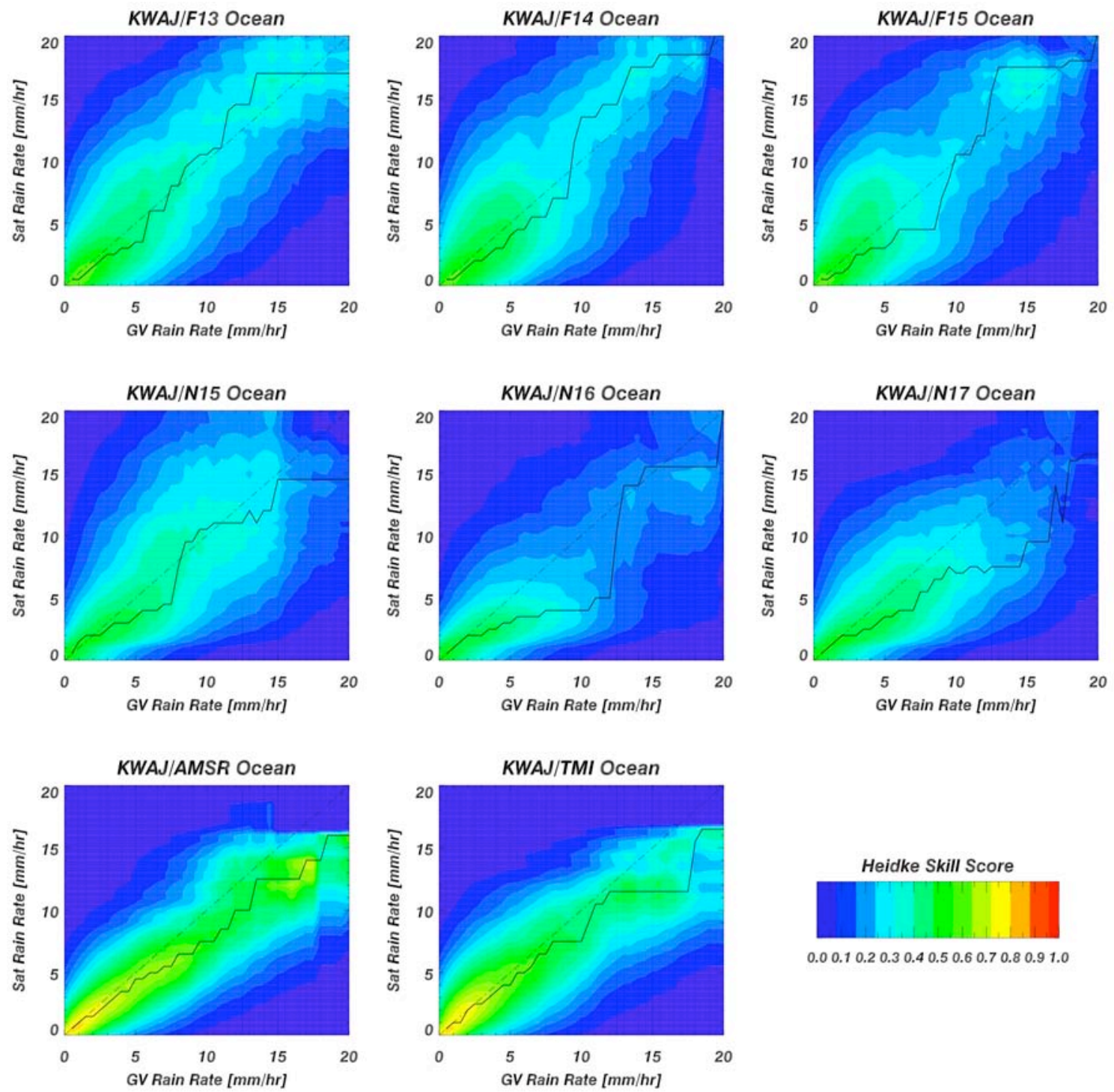

Fig. 12: Two-dimensional Heidke Skill Score plots for the various satellite and GV estimates. The line through the contours represents the maximum HSS for a given GV rain rate. 


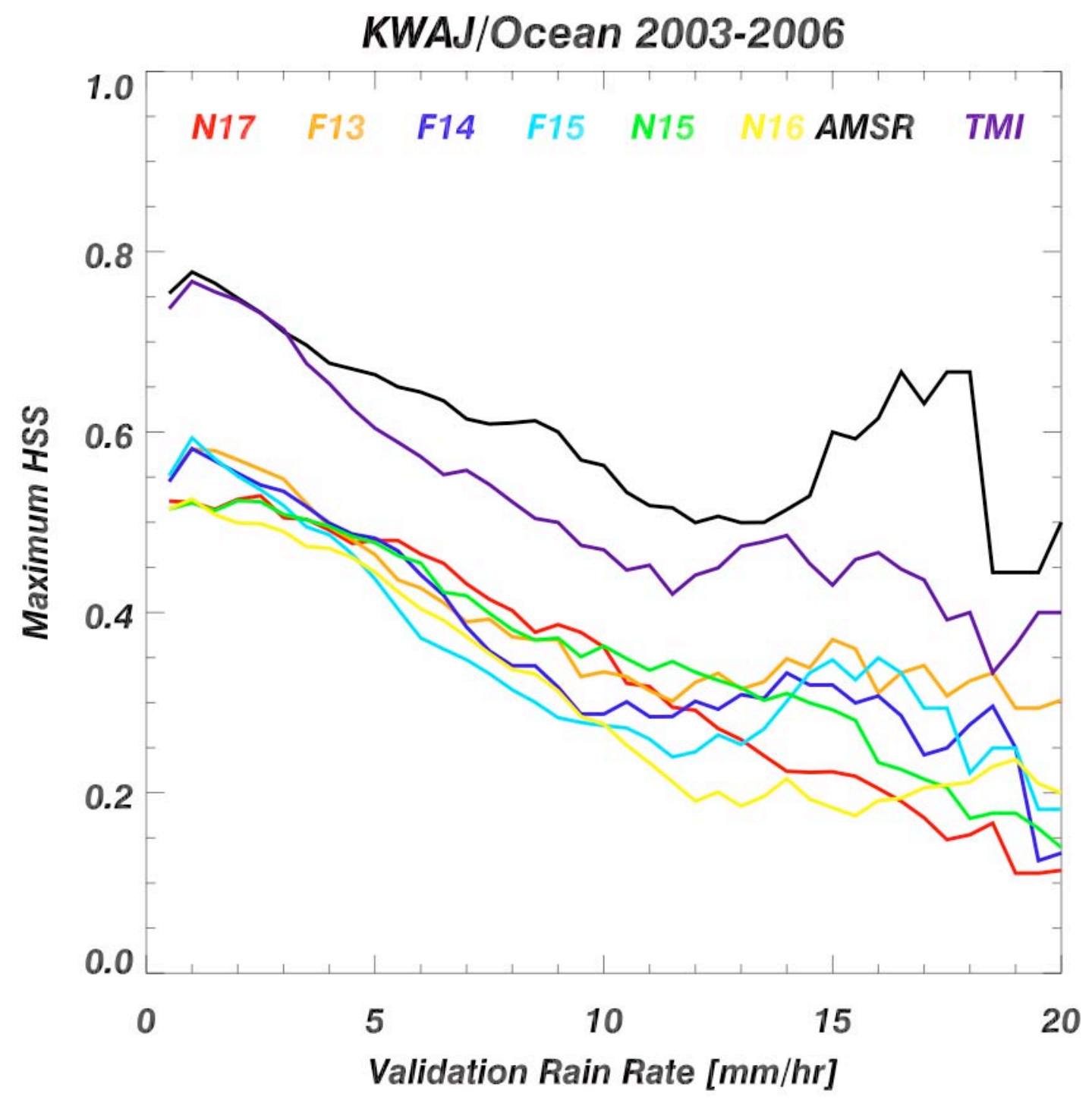

Fig. 13: Maximum Heidke Skill Scores for a given GV rain rate at KWAJ for each of the various satellites. Line colors specify the particular satellite estimate. 

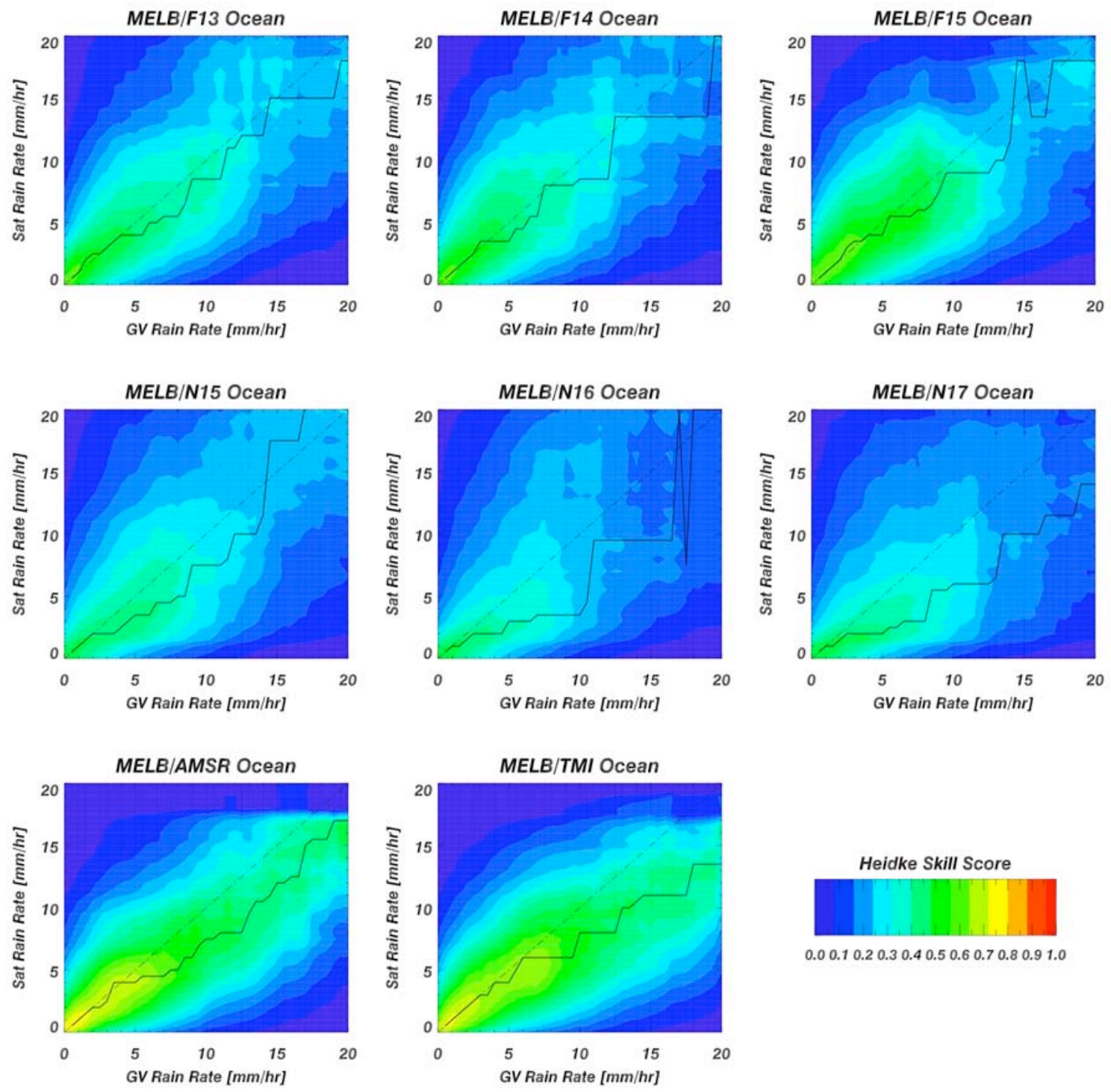

Fig. 14a: Same as Fig. 12, except over ocean areas at MELB. 

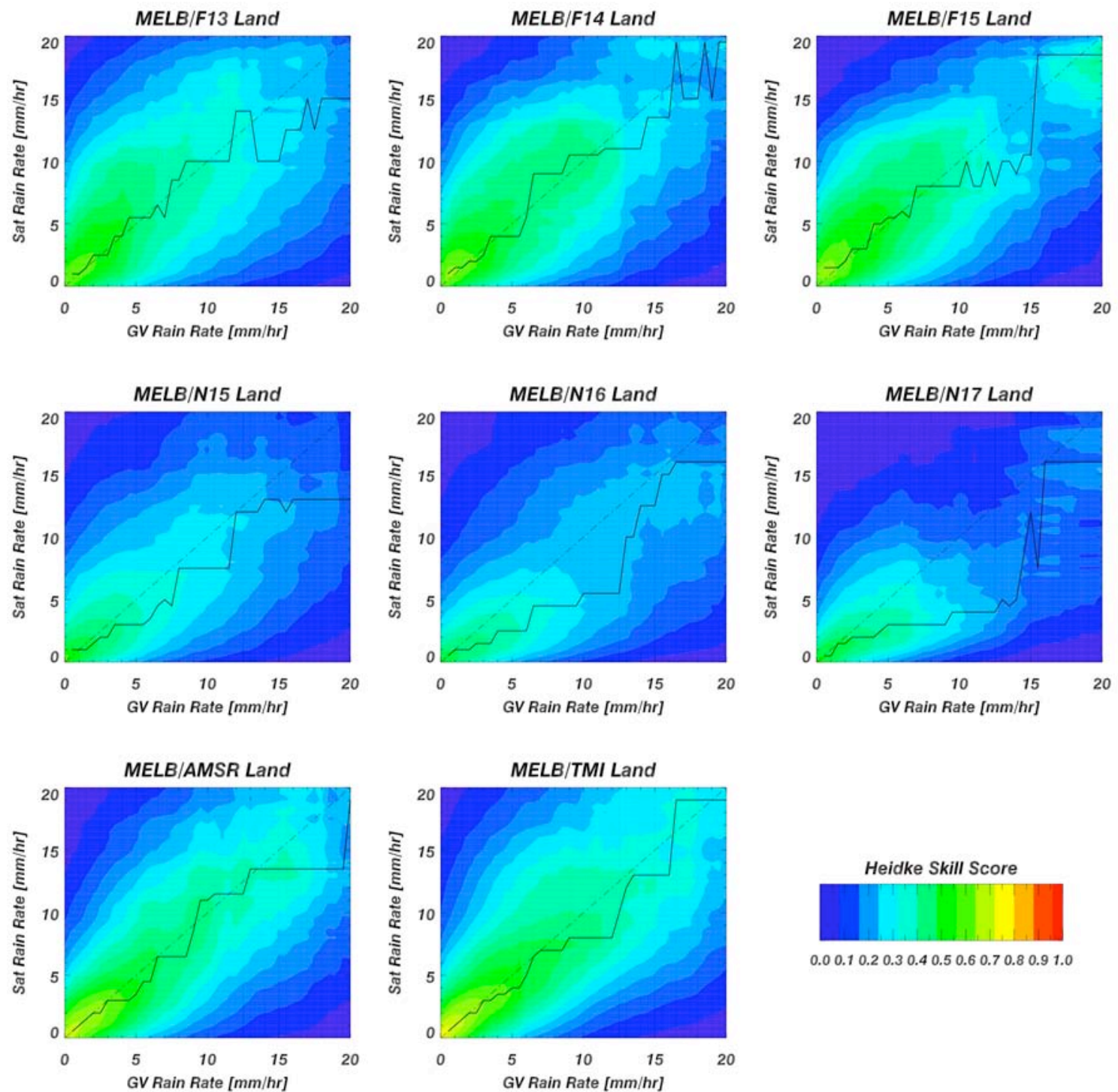

Fig. 14b: Same as Fig. 12, except for land areas over MELB. 

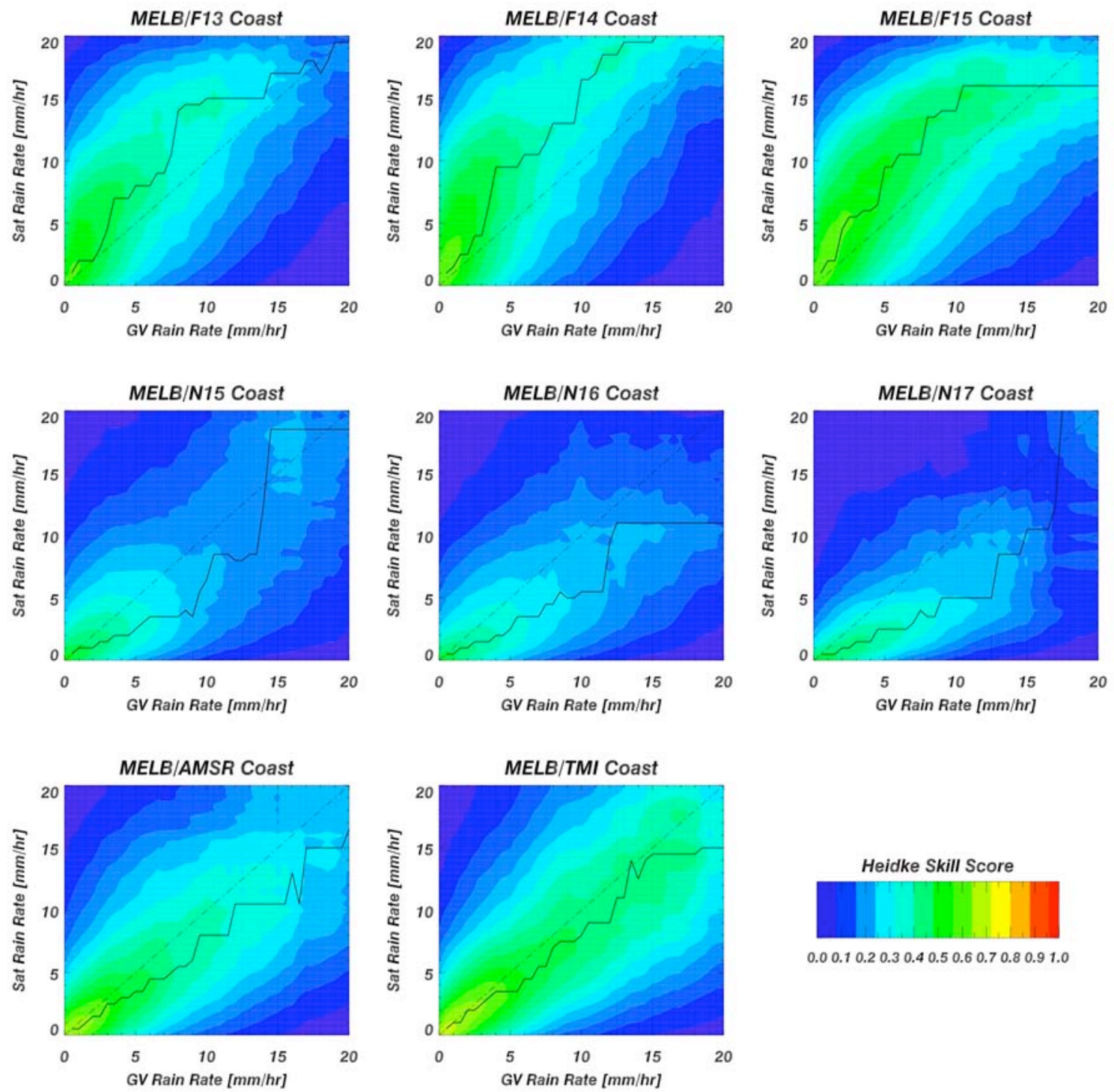

Fig. 14c: Same as Fig. 12, except for coastal areas over MELB. 

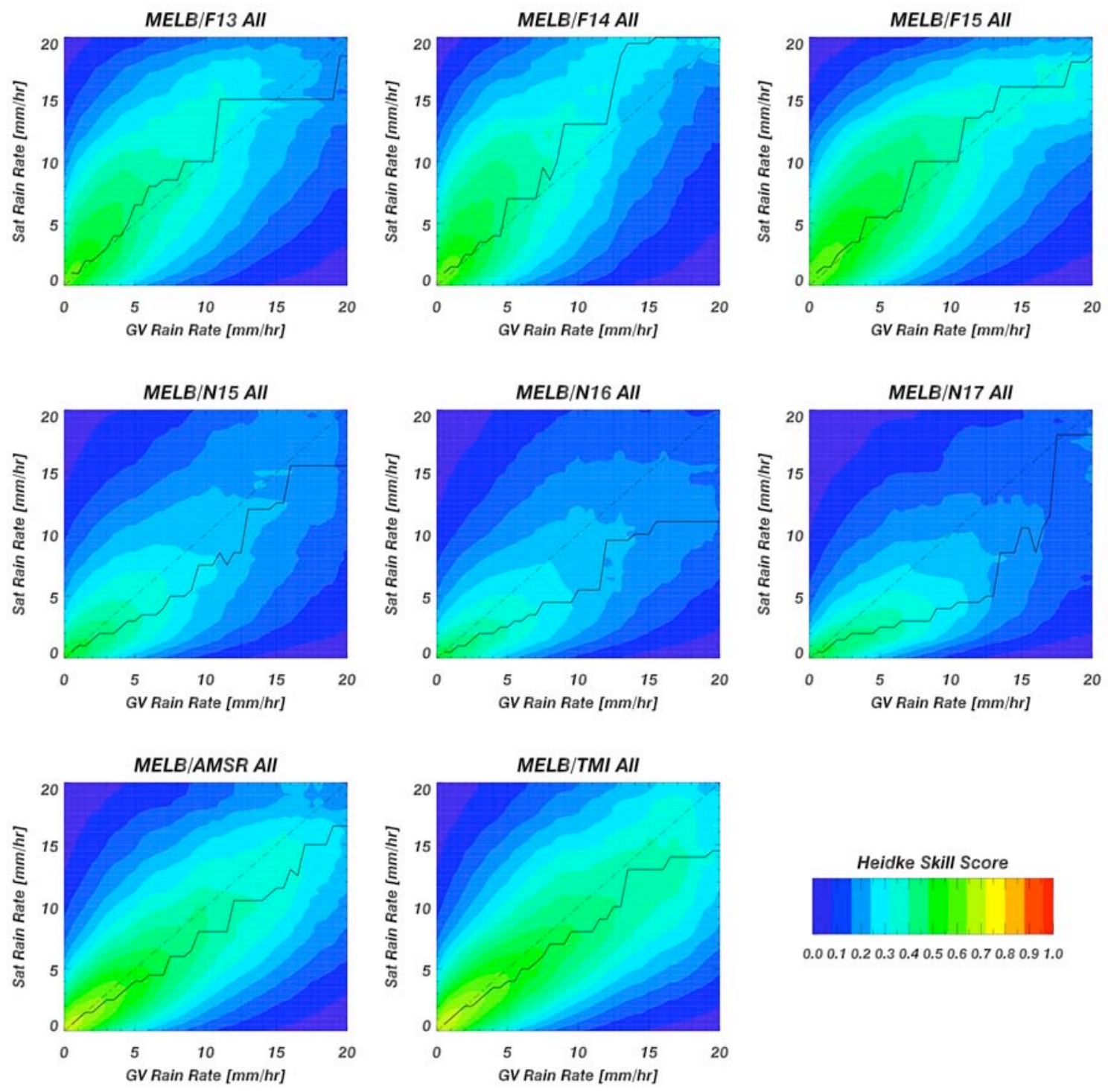

Fig. 14d: Same as Fig. 12, except for the entire GV domain over MELB. 

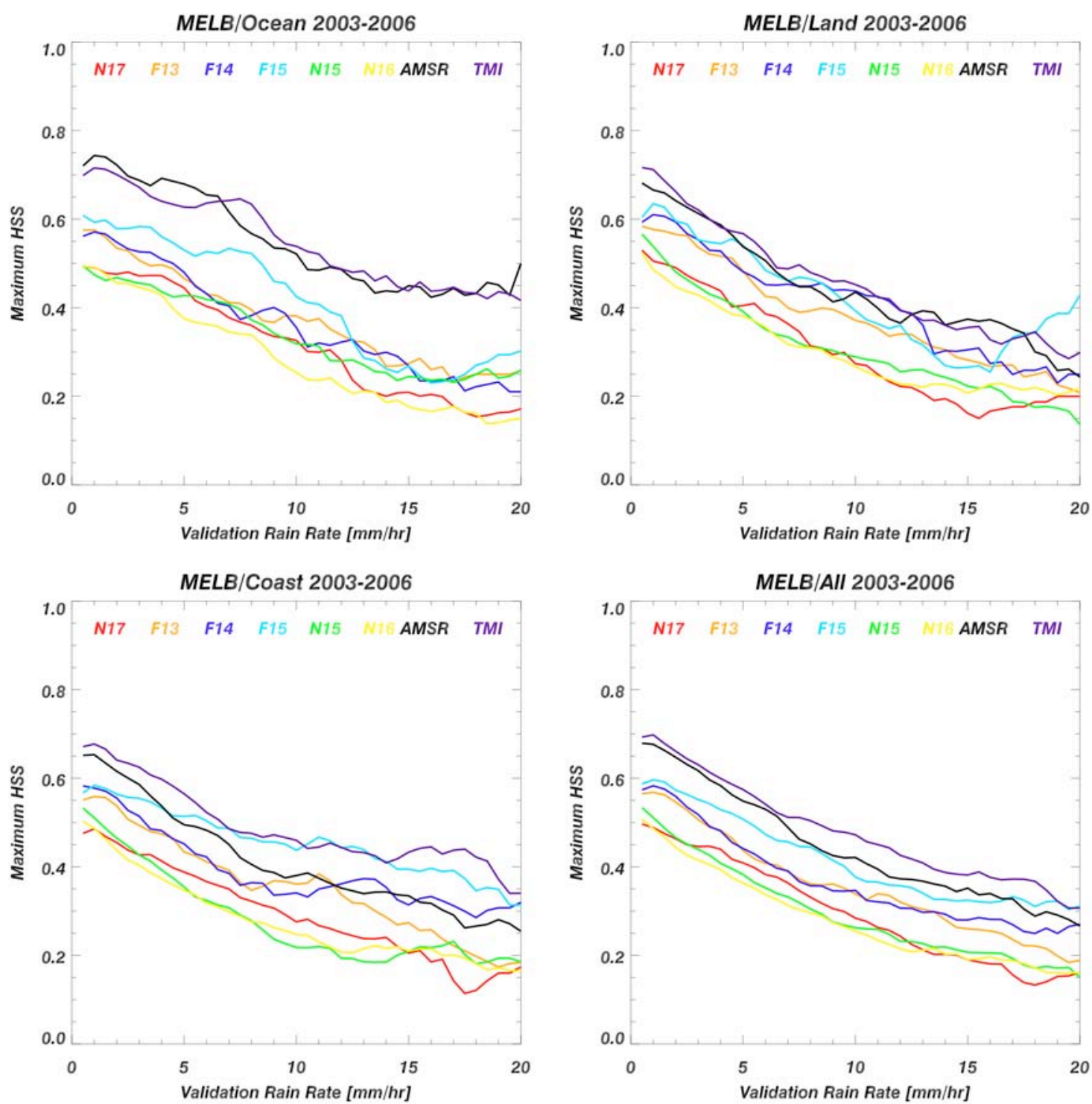

Fig 15: Maximum Heidke Skill Score for a given GV rain rate at MELB for the various satellites. The panels show these scores over "Ocean", "Land", "Coast" and "All" in the top-left, top-right, bottom-left and bottom-right panels, respectively. 